\title{
The Energy Budget of the Polar Atmosphere in MERRA
}

Richard I. CuLLATHER

Earth System Science Interdisciplinary Center, University of Maryland, College Park

MICHAEL G. BOSILOVICH

Global Modeling and Assimilation Office,

NASA Goddard Space Flight Center, Greenbelt, Maryland

Submitted to: Journal of Climate

Corresponding author address: Richard Cullather, \% NASA/GSFC Code 610.1, 8800 Grenbelt Road, Greenbelt, MD 20771.

E-mail: richard.cullather@nasa.gov 
Components of the atmospheric energy budget from the Modern Era Retrospective-

3 analysis for Research and Applications (MERRA) are eval uated in polar regions for the period

$4 \quad$ 1979-2005 and compared with previous estimates, in situ observations, and contemporary

5 reanalyses. Closure of the energy budget is reflected by the analysis increments term, which

6 results from virtual enthal py and latent heating contributions and averages $-11 \mathrm{~W} \mathrm{~m}^{-2}$ over the

7 north polar cap and $-22 \mathrm{~W} \mathrm{~m}^{-2}$ over the south polar cap. Total energy tendency and energy

8 convergence terms from MERRA agree closely with previous study for northern high latitudes

9 but convergence exceeds previous estimates for the south polar cap by 46 percent. Discrepancies

10 with the Southern Hemisphere transport are largest in autumn and may be related to differences

11 in topography with earlier reanalyses. For the Arctic, differences between MERRA and other

12 sources in TOA and surface radiative fluxes maximize in May. These differences are concurrent

13 with the largest discrepancies between MERRA parameterized and observed surface albedo. For

14 May, in situ observations of the upwelling shortwave flux in the Arctic are $80 \mathrm{~W} \mathrm{~m}^{-2}$ Iarger than

15 MERRA, while the MERRA downwelling longwave flux is underestimated by $12 \mathrm{~W} \mathrm{~m}^{-2}$

16 throughout the year. Over grounded ice sheets, the annual mean net surface energy flux in

17 MERRA is erroneously non-zero. Contemporary reanalyses from the Climate Forecast Center

18 (CFSR) and the Interim Re-Analyses of the European Centre for Medium Range Weather

19 Forecasts (ERA-I) are found to have better surface parameterizations, however these collections

20 are al so found to have significant discrepancies with observed surface and TOA energy fluxes.

21 Discrepancies among avai lable reanal yses underscore the challenge of reproducing credible

22 estimates of the atmospheric energy budget in polar regions. 


\section{Introduction}

The objective of this study is to examine the performance of the Modern Era

Retrospective-analysis for Research and Applications (MERRA) in representing the high latitude

26

27

28

29

atmospheric energy budget. MERRA was recently released by NASA's Global Modeling and Assimilation Office (GMAO). This effort, as well as a companion paper examining the atmospheric moisture budget (Cullather and Bosilovich, 2010), represent an initial examination of this reanalysis in the polar regions.

A quantitative knowledge of the flow, storage, and conversion of energy within the climate system has evolved with time as a result of contributions made by improvements in the observing system and by numerical atmospheric reanalyses (e.g., Fasullo and Trenberth, 2008). In the polar regions the energy budget and its variability are frequently used as a diagnostic for understanding rapidly changing conditions including glacial mass balance and perennial sea ice reduction (e.g., Porter et al., 2010). As noted in Cullather and Bosilovich (2010), numerical reanalyses are widely used in polar research for evaluating polar processes, as boundary conditions for limited area atmosphere and ocean-sea ice models, and as a first-order validation for climate models. However reanal yses inevitably contain inaccuracies resulting from limitations in the observing system, inconsistencies between differing observations, and incomplete knowledge of the physical processes that are represented in the assimilating weather forecast model. In particular, surface al bedo characteristics over polar oceans and high latitude cloud properties are both associated with important but complex energy feedback mechanisms that have historically been poorly simulated (Randall et al., 1998). An initial evaluation of the high latitude energy budget in a reanalysis record is therefore a constructive activity. Some questions of interest pertaining to this study are as follows. 
- What are the spatial and temporal patterns of energy budget components in MERRA, and how do they compare with previous studies and contemporary reanalyses?

- How do MERRA surface fluxes compare with in situ field studies?

- What is the nature of adjustment terms in the energy budget?

Section 2 provides an overview of the MERRA data set and method. An evaluation of the

51 atmospheric energy balance in polar regions is given in section 3. A discussion of these

52 comparisons is then given in section 4.

53

54 2. MERRA description and method

Specification of the MERRA system is given in Cullather and Bosilovich (2010) and

56 Rienecker et al. (2010). MERRA utilizes the incremental anal ysis update assi milation method

57 (IAU; Bloom et al., 1996). In this method, a tendency is computed from the difference between

58 an initial 6-hourly analysis field and the background forecast model state. The forecast model is

59 then run a second time over the six-hour interval using this tendency as an additional forcing

60 term. The resulting MERRA product is then composed of dynamically-consistent one-hourly

61 fields that are incrementally corrected to observation every six hours. Thus atmospheric budgets

62 as they are constructed in the GEOS-5 AGCM- and their analysis increments are maintained

63 within MERRA to the accuracy limited by round-off and data compression errors.

64 Foll owing a form similar to Trenberth (1997), the MERRA total energy equation

65 integrated over the atmospheric column may be written as

66

$$
\frac{\partial A_{E}}{\partial t}+\nabla \cdot \tilde{\mathbf{F}}_{A}=R_{t o p}+F_{s f c}+\left.L_{v} \frac{\partial W_{v}}{\partial t}\right|_{C H M}+\left[L_{v} \frac{\partial W_{v}}{\partial t}-\left.L_{f} \frac{\partial W_{i}}{\partial t}\right|_{F L}+A N A_{(E)}-Q_{N U M}\right.
$$


67 where $A_{E}$ is total energy in the atmospheric column, $\tilde{\mathbf{F}}_{A}$ is the horizontal transport of total

68 atmospheric energy, $R_{\text {top }}$ is the downward net radiative flux at the top of the atmosphere (TOA),

$69 F_{s f c}$ is the upwelling net surface flux, $L_{v}$ is the latent heat of vaporization, $L_{f}$ is the latent heat of

70 fusion, $W_{v}$ is column-integrated water vapor (precipitable water), $W_{i}$ is col umn-integrated cloud

71 ice condensate, $A N A_{(E)}$ is the sum of analysis increments from the IAU method, and $Q_{N U M}$ is the

72 sum of spurious numerical adjustments. The time rate of change in total atmospheric energy

73 storage $A_{E}$ is expressed as

74

$$
\frac{\partial A_{E}}{\partial t}=L_{v} \frac{\partial W_{v}}{\partial t}-L_{f} \frac{\partial W_{i}}{\partial t}+\frac{\partial}{\partial t}\left\{\int_{p_{\text {top }}}^{p_{\text {sc }}}\left(c_{P} T_{v}+\Phi_{S}+k\right) \frac{d p}{g}\right\},
$$

75 where $p_{s f c}$ is surface pressure, $p_{\text {top }}$ is the fixed pressure at the top model level which is $0.01 \mathrm{hPa}$,

$76 c_{P}$ is the specific heat of the atmosphere at constant pressure, $T_{v}$ is virtual temperature, $\Phi_{S}$ is

77 surface geopotential, $k=\frac{1}{2}|\tilde{\mathbf{V}}|^{2}$ is kinetic energy, and $g$ is the gravity constant. The product $c_{p} T_{v}$

78 is referred to as virtual enthalpy. The divergence term may be expanded as follows:

79

$$
\nabla \cdot \tilde{\mathbf{F}}_{A}=\nabla \cdot \int_{p_{t o p}}^{p_{\text {scc }}}\left(L_{v} q_{v}-L_{f} q_{i}\right) \tilde{\mathbf{V}} \frac{d p}{g}+\nabla \cdot \int_{p_{t o p}}^{p_{s c c}} c_{P} T_{v} \cdot \tilde{\mathbf{V}} \frac{d p}{g}+\nabla \cdot \int_{p_{t o p}}^{p_{\text {gcc }}} \Phi \cdot \tilde{\mathbf{V}} \frac{d p}{g}+\nabla \cdot \int_{p_{t o p}}^{p_{\text {scc }}} k \cdot \tilde{\mathbf{V}} \frac{d p}{g}
$$

80 where $\Phi$ is geopotential within the atmospheric column. The net upward surface flux is given as

$$
F_{s f c}=Q_{H}+Q_{E}+L_{f} P_{s}-R_{s f c}
$$

82 where $Q_{H}$ and $Q_{E}$ are the upwelling surface turbulent sensible and latent heat fluxes, the product

$83 L_{f} P_{s}$ is latent heating resulting from solid precipitation, and $R_{s f c}$ is the net downward radiative

84 flux at the surface. The tendency imposed by the analysis increments $A N A_{(E)}$ represents the

85 summation of latent heat, virtual enthalpy, kinetic, and geopotential energy term contributions.

86 Finally, $Q_{N U M}$ in (1) denotes the contribution of spurious residuals resulting from inertial terms, 
87 the discretization of the thermodynamic equation, coordinate remapping during model

88 integration, and time-truncation errors. The relation between MERRA variables and equation

89 notation is given in the appendix.

90 The approach of this study is to evaluate MERRA val ues against prior studies for large-

91 scale areal averages of the terms in (1-4) over fixed polar regions as shown in Fig. 1, with a

92 particular focus on the polar caps. Studies for comparison incl ude Nakamura and Oort (1988),

93 Genthon and Krinner (1998), Serreze et al . (2007), and Porter et al. (2010). Nakamura and Oort

94 (1988) produced budget esti mates for both polar caps using the ocean flux values of Levitus

95 (1984), composite satellite data from the period 1966-1977, and atmospheric circulation statistics

96 from Oort (1983) which are largely based on the upper air station network. Nakamura and Oort

97 (1988) found the observational network insufficient for computing atmospheric energy transport

98 into the south polar cap and instead produced output from the NOAA Geophysical Fluid

99 Dynamics Laboratory GCM. Genthon and Krinner (1998) used the 15-year re-analysis of the

100 European Centre for Medium-Range Weather Forecasts (ECMWF) (ERA-15; Gibson et al.,

101 1997) for the period 1979-1993 to eval uate the south polar cap. Serreze et al. (2007) examined

102 the north polar cap and Arctic Ocean domains using the more recent 40-year re-analysis of

103 ECMWF (ERA-40; Uppala et al., 2005) and the National Centers for Environmental

104 Prediction/National Center for Atmospheric Research Reanalyses (NCEP/NCAR; Kal nay et al., 105 1996) for the period 1979-2001. Serreze et al. (2007) al so examined TOA radiative fluxes from

106 the Earth Radiation Budget Experiment for the study period February 1985 to April 1989

107 (ERBE; Barkstrom, 1984). Porter et al. (2010) similarly examined the north polar cap energy

108 budget for the period November 2000 to October 2005 using the 25-year Japanese Re-Analysis

109 (JRA-25; Onogi et al., 2007), and satellite data from the Clouds and the Earth's Radiant Energy 
110 System (CERES; Wielicki et al., 1996) product. In support of budget comparisons with these

111 previous studies, the eval uation of near-surface state variables against in situ station observations

112 is also instructive.

113 Corresponding values for surface and TOA energy fluxes are also tabulated for two

114 contemporary reanalyses for comparison: the ECMWF Interim product (ERA-I; Simmons et al.,

115 2007) and the NCEP Climate Forecast System Reanalysis (CFSR; Saha et al., 2010). The ERA-I

116 was produced at T-255 spectral resolution, which is similar to the grid resolution of MERRA.

117 Energy flux fields are produced from 12-hour forecasts initialized by 4D-Var assi milation.

118 Monthly fields of the ERA-I were obtained for the years 1989-2005 at a reduced resolution of

$1191.5^{\circ} \times 1.5^{\circ}$. The CFSR utilize a coupled atmosphere-ocean model for the initial guess field and

120 an interactive sea ice model and was produced at T-382 spectral resolution. Model variables are

121 produced from 6-hour forecasts. Energy flux fields from the CFSR were obtained at full spatial

122 resolution.

123 Evidence of an evolving climate system in polar regions - particularly for the Arctic (e.g.,

124 Porter et al., 2010)- motivate an exclusion of the most recent years in the available MERRA time

125 series for an averaging period. The results presented here are for the years 1979-2005.

127 3. Atmospheric energy budget

128 a. Analysis increments

129 Terms of the atmospheric energy budget averaged over the period 1979-2005 from

130 MERRA are shown in Table 1 for the polar regions defined in Fig. 1. The far right column

131 indicates budget adjustment quantities. As noted earlier, artificial moisture filling and chemistry

132 parameterization terms of the energy budget from equation (1) have essentially zero magnitude. 
133 Not shown, the spatial pattern of the spurious residual $Q_{N U M}$ is characterized by alternating 134 positive and negative values in regions of steep topography. Averages taken over limited areas 135 may produce al iasing of these oscillating values. For example, $Q_{N U M}$ averages $1.5 \mathrm{~W} \mathrm{~m}^{-2}$ over 136 the Greenland Ice Sheet. But in general, $A N A_{(E)}$ is the largest adjustment quantity of interest in 137 the atmospheric energy budget, and its spatial patterns are shown in Fig. 2. Here, positive values 138 indicate an energy surplus in the bal ance equation while negatives indicate a deficit. The 139 magnitude is a measure of closure obtainable by physical terms. The spatial patterns shown in 140 Fig. 2 are complex, vary with time, and are typically dissimilar to the patterns of the analysis 141 increments for the atmospheric moisture budget shown by Cullather and Bosilovich (2010). As noted previously, analysis increments for the energy budget are the summation of 143 contributions from latent heat, virtual enthalpy, kinetic, and geopotential energy terms. Of these 144 four, the contribution to $A N A_{(E)}$ from virtual enthalpy is large for monthly and annual averages in 145 both polar cap regions, while analysis increments from latent heating are al so significant for the 146 north polar cap. For the Northern Hemisphere pol ar region, negative values for $A N A_{(E)}$ are found 147 over the Arctic Ocean, while positive values are present over surrounding lower latitudes. Mean 148 annual amounts less than $-40 \mathrm{~W} \mathrm{~m}^{-2}$ are present in the vicinity of the North Pole with smaller 149 magnitudes over Greenland and marginal seas. Seasonally, these magnitudes are larger in 150 summer than in winter, however the val ues do not approach the local imbal ances of greater than $151100 \mathrm{~W} \mathrm{~m}^{-2}$ that are shown for the ERA-40 in Serreze et al. (2007). For the average over the north 152 polar cap, $A N A_{(E)}$ ranges from $-4 \mathrm{~W} \mathrm{~m}^{-2}$ in February to $-17 \mathrm{~W} \mathrm{~m}^{-2}$ in June.

In Cullather and Bosilovich (2010), MERRA analysis increments for the atmospheric 154 moisture budget were shown to be characterized by closed contours denoting upper air stations in 155 coastal Greenland and Antarctica. Although signatures of upper air station locations are not as 
156 evident in the $A N A_{(E)}$ field as in the analysis increments field for the atmospheric moisture

157 budget, a dipole is apparent in Fig. 2a in the vicinity of Hudson Strait with centers near Kuujjuaq $158\left(58^{\circ} \mathrm{N}, 68^{\circ} \mathrm{W}\right)$ and Cape Dorset $\left(64^{\circ} \mathrm{N}, 77^{\circ} \mathrm{W}\right)$. Averaged over the north polar cap and the period $1591979-2005, A N A_{(E)}$ is $-11 \mathrm{~W} \mathrm{~m}^{-2}$. The temporal variability of $A N A_{(E)}$ in the Arctic al so differs 160 markedly from the analysis increments field of the atmospheric moisture budget presented in 161 Cullather and Bosilovich (2010). Changes in the high latitude atmospheric moisture budget 162 analysis increments were largely found to be associated with the introduction of data from the 163 Advanced Microwave Sounding Unit (AMSU) in November 1998, which has a global impact on 164 MERRA (Bosilovich et al., 2010). In contrast, the $A N A_{(E)}$ time series for the north polar cap 165 indicates changes which are not concurrent with satellite observing system changes. The 166 magnitude of energy budget analysis increments for the north polar cap averages less than $16710 \mathrm{~W} \mathrm{~m}^{-2}$ for the period 1979-1991, approximately $18 \mathrm{~W} \mathrm{~m}^{-2}$ over the period 1992-1997, and $1689 \mathrm{~W} \mathrm{~m}^{-2}$ thereafter. These shifts may be due to changes in the surface observing system or in 169 atmospheric conditions.

170 In the Southern Hemisphere, the MERRA energy budget analysis increments term-as 171 shown in Fig. 2b- has a larger magnitude than for the north polar cap, with amounts of greater 172 than $(-) 80 \mathrm{~W} \mathrm{~m}^{-2}$ over Victoria Land and regions of northern Queen Maud Land in East

173 Antarctica. Over the south polar cap, $A N A_{(E)}$ ranges from $-27 \mathrm{~W} \mathrm{~m}^{-2}$ in February to $-20 \mathrm{~W} \mathrm{~m}^{-2}$ 174 in August and September. The annual average of $A N A_{(E)}$ is comparatively smaller over the lower 175 latitudes of the Southern Ocean as seen in Fig. 2b. There is a considerable annual cycle for the 176 Southern Ocean domain ranging from $-40 \mathrm{~W} \mathrm{~m}^{-2}$ in January and February to $-9 \mathrm{~W} \mathrm{~m}^{-2}$ in June.

177 The year to year time series for the south polar cap is highly variable and ranges from $178-37 \mathrm{~W} \mathrm{~m}^{-2}$ in 1983 to $-9 \mathrm{~W} \mathrm{~m}^{-2}$ in 1998 . The analysis increments time series for the south polar 
179 cap energy budget is uncorrel ated with that of the north polar cap, and its relation to changes in 180 the observing system is also not readily apparent. But over the data-sparse Southern Ocean 181 domain there is a discontinuity in the $A N A_{(E)}$ time series in 1998 that is likely associated with the 182 introduction of AMSU. Southern Ocean analysis increments average $-21.8 \mathrm{~W} \mathrm{~m}^{-2}$ prior to 1998 , 183 and $-26.7 \mathrm{~W} \mathrm{~m}^{-2}$ thereafter.

\section{b. Total atmospheric energy tendency}

In both the north and south polar caps, the MERRA total energy tendency is near zero for annual averages and is small for months of solstice, as shown in Table 1. But there is an oscillatory annual cycle for the tendency terms as seen in Fig. 3. For the north polar cap, the tendency term reaches a maximum of $26 \mathrm{~W} \mathrm{~m}^{-2}$ in April and a minimum of $-26 \mathrm{~W} \mathrm{~m}^{-2}$ in

September. This annual cycle agrees very closely with val ues from other reanal yses as reported by Porter et al. (2010), Serreze et al. (2007), and from the observational study of Nakamura and Oort (1988). The RMS difference of monthly means with MERRA is only $4 \mathrm{~W} \mathrm{~m}^{-2}$ for both NCER/NCAR and JRA-25 as reported by Porter et al. (2010), less than $1 \mathrm{~W} \mathrm{~m}^{-2}$ for the ERA-40 as reported by Serreze et al. (2007), but $10 \mathrm{~W} \mathrm{~m}^{-2}$ for Nakamura and Oort (1988). In general the reanal yses are more similar to each other than to the earlier Nakamura and Oort time series.

For the south polar cap, the total energy tendency in MERRA ranges from a minimum of $197-16 \mathrm{~W} \mathrm{~m}^{-2}$ in A pril to $30 \mathrm{~W} \mathrm{~m}^{-2}$ in November. As seen in Fig. 3b, the annual cycle is less 198 sinusoidal than in the Northern Hemi sphere, with the November peak offsetting an average 199 negative tendency that extends from January through July. The RM S difference with monthly 200 val ues reported by Nakamura and Oort (1988) as compared to MERRA is $13 \mathrm{~W} \mathrm{~m}^{-2}$, although 201 each month is within the standard deviation of MERRA for the 1979-2005 period. As seen in 
202 equation (4), the MERRA energy tendency incorporates the cloud ice latent heating and kinetic 203 energy terms which are not considered in other studies. For monthly means over the regions 204 examined, however, these terms are negligible.

c. Energy convergence and transport

207 As seen in equation (3), the divergence term is composed of contributions from latent 208 heat, virtual enthalpy, kinetic, and geopotential energy terms. For the north polar cap, the annual 209 cycle of energy convergence from MERRA consists of values greater than $100 \mathrm{~W} \mathrm{~m}^{-2}$ during 210 winter months September through March and a minimum of $72 \mathrm{~W} \mathrm{~m}^{-2}$ in May, as seen in

211 Fig. 3a. Porter et al. (2010) present annual cycles of energy convergence computed as a residual 212 using several combinations of reanalyses and radiative flux data sets for the period 2000-2005, 213 while Serreze et al. (2007) present ERA-40 and NCEP/NCAR reanalysis average monthly values

214 for the period 1979-2001. While there is agreement in larger energy convergence in winter, there 215 is considerable variability among the data sets on the months of the minimum and maximum 216 value, with May providing a spread of $40 \mathrm{~W} \mathrm{~m}^{-2}$ among the various methods. MERRA values 217 concurrent with these previous studies are found within this large range.

218 Figure 4a indicates that the average poleward energy transport across $70^{\circ} \mathrm{N}$ is zonally 219 asymmetric and is focused at preferred longitudes which are associated with the mean longwave 220 circulation patterns in the middle troposphere (Serreze et al., 2007). In comparison to energy 221 transports across $70^{\circ} \mathrm{N}$ from ERA-40 as reported by Serreze et al. (2007), MERRA transports 222 shown in Fig. 4a are comparable but with some differences. First, the poleward (positive) flux 223 centered near $315^{\circ} \mathrm{E}\left(45^{\circ} \mathrm{W}\right)$ has a smal ler zonal extent than is shown in Serreze et al. (2007). 224 This may be due to the higher spatial resolution of MERRA and the role of the Greenland Ice 
225 Sheet topography in defining the mid-tropospheric trough pattern over eastern North America.

226 Second, the wintertime poleward transport near $150^{\circ} \mathrm{E}$ is shown in MERRA to be greater than

$22720 \cdot 10^{9} \mathrm{~W} \mathrm{~m}^{-1}$. This is stronger by one contour level $\left(5 \cdot 10^{9} \mathrm{~W} \mathrm{~m}^{-1}\right)$ than that shown by

228 Serreze et al. for ERA-40. But in general the average meridional transport patterns of MERRA 229 and ERA-40 are remarkably similar.

230 In the Southern Hemisphere, prior studies on atmospheric energy convergence are not as

231 recent. However comparisons to MERRA may be made using Nakamura and Oort (1988) and

232 Genthon and Krinner (1998). Using GCM output, Nakamura and Oort (1988) estimated a mean

233 annual energy convergence across $70^{\circ} \mathrm{S}$ of $95 \mathrm{~W} \mathrm{~m}^{-2}$, which is $23 \mathrm{~W} \mathrm{~m}$ less than shown for

234 MERRA in Table 1. As seen in Fig. 3b, the annual cycle in MERRA contains a broad maximum

235 over winter months and a short period of minimum of values less than $100 \mathrm{~W} \mathrm{~m}^{-2}$ in December, 236 January, and February. In contrast Nakamura and Oort (1988) indicate lower amounts in the 237 autumn, and their annual cycle is generally more sinusoidal. Nakamura and Oort (1988) and 238 MERRA monthly energy convergence values are comparable over the months June to October 239 but MERRA is larger by $45 \mathrm{~W} \mathrm{~m}^{-2}$ in January. More recently, Genthon and Krinner (1998) 240 produced seasonal averages and zonal distributions of energy transport using ERA-15 for the 241 period 1979-1993. The annual atmospheric energy convergence derived from ERA-15 of

$24281 \mathrm{~W} \mathrm{~m}^{-2}$ is considerably smaller than corresponding values of either MERRA or Nakamura and 243 Oort (1988). Seasonally, the largest differences between MERRA and Genthon and

244 Krinner (1998) ERA-15 val ues are in autumn. Energy convergence for the south polar cap for

245 March-A pril-May averages $134 \mathrm{~W} \mathrm{~m}^{-2}$ in MERRA, while Genthon and Krinner (1998) reported

$24679 \mathrm{~W} \mathrm{~m}^{-2}$. The spatial distribution of energy transports al ong the $70^{\circ} \mathrm{S}$ parallel is strongly

247 dependent on the meandering coastline, such that spatial resolution and topography are 
248 significant. Thus the differences betwen MERRA and ERA-15, though large, may partially 249 result from differing model grids. Additionally, ERA-15 was known to employ a defective 250 orography over the ice sheet (Uppal a et al ., 2005). A visual inspection of Genthon and Krinner 251 (1998) results indicates that the ERA-15 mean annual poleward transport is less than MERRA 252 near $30^{\circ} \mathrm{E}$, an intersection point between the $70^{\circ} \mathrm{S}$ parallel and the East Antarctic coastal 253 escarpment. For this location, Genthon and Krinner (1998) plot amounts of between 2 and $2543 \cdot 10^{9} \mathrm{~W} \mathrm{~m}^{-1}$ while MERRA values are greater than $5 \cdot 10^{9} \mathrm{~W} \mathrm{~m}^{-1}$. Additionally Genthon and 255 Krinner (1998) indicate an annual mean equatorward energy transport in the Ross Sea, while 256 MERRA indicates an average poleward flux. MERRA and ERA-15 share some general 257 characteristics of the meridional energy transport including a directional change with season in 258 the South Pacific region between $180^{\circ} \mathrm{E}$ and $270^{\circ} \mathrm{E}$ from poleward during winter months to 259 equatorward in summer, as shown in Fig. 4b. The figure al so shows an opposing seasonal 260 reversal between $270^{\circ} \mathrm{E}$ and $300^{\circ} \mathrm{E}$ in MERRA, and this is al so reflected in Genthon and Krinner 261 (1998).

262

d. TOA radiative fluxes

For the north polar cap, MERRA TOA radiative fluxes are compared to ERBE (Serreze 265 et al., 2007) and CERES (Porter et al., 2010). With the exception of midsummer months, the 266 Arctic TOA radiative flux in MERRA is mainly directed upwards $\left(R_{t o p}<0\right)$, with an annual 267 average shown in Table 1 of $-110 \mathrm{~W} \mathrm{~m}^{-2}$. Annual estimates from ERBE and CERES are within 268 the standard deviation of this value. On the monthly time scale, the largest differences are for the 269 month of May, where the MERRA $1979-2005$ value of $-23 \mathrm{~W} \mathrm{~m}^{-2}$ compares with $-53 \mathrm{~W} \mathrm{~m}^{-2}$ in 270 ERBE (Serreze et al., 2007) and $-37 \mathrm{~W} \mathrm{~m}^{-2}$ in CERES (Porter et al., 2010). Using MERRA 
271 averages concurrent with these satellite records, MERRA is less than satellite estimates for May 272 by $29 \mathrm{~W} \mathrm{~m}^{-2}$ as compared to ERBE and by $12 \mathrm{~W} \mathrm{~m}^{-2}$ as compared to CERES. In July, CERES

273 indicates a net downwards TOA flux of $21 \mathrm{~W} \mathrm{~m}^{-2}$ compared to a $1 \mathrm{~W} \mathrm{~m}^{-2}$ upwards flux in

274 MERRA, while ERBE and MERRA concurrent July values are equal. For other months, the 275 differences are small.

276 Table 2 also presents $R_{\text {top }}$ values for MERRA in comparison to contemporary reanalyses 277 of the ERA-I and CFSR for the period 1989-2005. As seen in Table 2 for the north polar cap, the 278 MERRA annual net TOA radiative flux is greater than for the other two reanalyses by $4 \mathrm{~W} \mathrm{~m}^{-2}$. 279 Again, the largest differences are for the spring time period. For the month of May, $R_{t o p}$ for the 280 ERA-I averages $-34 \mathrm{~W} \mathrm{~m}^{-2}$ while the CFSR value is $-36 \mathrm{~W} \mathrm{~m}^{-2}$, and MERRA again averages $281-23 \mathrm{~W} \mathrm{~m}^{-2}$ for $1989-2005$. Most of this difference is associated with the upwelling shortwave 282 flux. For the month of May, the MERRA TOA upwelling shortwave flux is less than CFSR and 283 ERA-I by $15 \mathrm{~W} \mathrm{~m}^{-2}$ and $18 \mathrm{~W} \mathrm{~m}^{-2}$, respectively. It is noted that CFSR incorporates an 11-year 284 solar cycle while MERRA and ERA-I use climatological solar forcing, and that ERA-I uses a 285 larger solar constant value than MERRA. For the north polar cap, differences in incoming solar 286 radiation between MERRA and CFSR are as large as $\pm 3 \mathrm{~W} \mathrm{~m}^{-2}$ for a given month, but average 287 less than $1 \mathrm{~W} \mathrm{~m}^{-2}$. Differences between ERA-I and MERRA are as large as $9 \mathrm{~W} \mathrm{~m}^{-2}$ for a given 288 month, and average $3 \mathrm{~W} \mathrm{~m}^{-2}$. For the south polar cap, the TOA net radiative flux remains negative throughout the year.

290 Comparisons to both ERBE data and the values from Nakamura and Oort (1988) indicate that the 291 annual net TOA radiative flux magnitude in MERRA is too large, and that the discrepancy is 292 largest during winter months. The 1979-2005 average net flux as shown in Table 1 for MERRA 293 is $-101 \mathrm{~W} \mathrm{~m}^{-2}$. This compares with $-90 \mathrm{~W} \mathrm{~m}^{-2}$ from the historical satel lite data used in 
294 Nakamura and Oort (1988), and $-95 \mathrm{~W} \mathrm{~m}^{-2}$ from ERBE for the period February 1985 to April 2951989 (Briegleb and Bromwich, 1998). The 1979-2005 annual average for $R_{t o p}$ is by chance equal 296 to the 1985-1989 time period for MERRA. In the annual cycle, the differences with satellite 297 observations are associated with the winter season. For the months of June, July, and August, the 298 average flux from Nakamura and Oort (1988) is $-131 \mathrm{~W} \mathrm{~m}^{-2}$, and from ERBE, $-134 \mathrm{~W} \mathrm{~m}^{-2}$. 299 For MERRA, the corresponding value is $-142 \mathrm{~W} \mathrm{~m}^{-2}$ for both 1979-2005 and 1985-1989 time 300 periods. In these winter months, the difference between MERRA and satellite values is al most 301 entirely composed of the outgoing longwave component.

302 Values for the south polar cap from ERA-I and CFSR reanal yses tend to agree more 303 closely with MERRA than with values from satellite data sets. For the 1989-2005 period, the net 304 TOA radiative flux shown in Table 2 averages $-101 \mathrm{~W} \mathrm{~m}^{-2}$ for MERRA, $-109 \mathrm{~W} \mathrm{~m}^{-2}$ for CFSR, 305 and $-102 \mathrm{~W} \mathrm{~m}^{-2}$ for ERA-I. In the annual cycle, the MERRA upwelling longwave flux is less 306 than the other two reanalyses by $3 \mathrm{~W} \mathrm{~m}^{-2}$ in spring and up to $7 \mathrm{~W} \mathrm{~m}^{-2}$ in autumn. The CFSR 307 upwelling shortwave flux is greater than the other two reanal yses by more than $10 \mathrm{~W} \mathrm{~m}^{-2}$ in 308 December and January, and the ERA-I solar constant difference with the other two reanalyses 309 accounts for $3 \mathrm{~W} \mathrm{~m}^{-2}$ on the annual average. The time series of MERRA TOA radiative fluxes indicate potentially spurious trends in

311 both polar regions. Over north and south polar caps, year to year variability in $R_{\text {top }}$ resembles that 312 of the energy budget analysis increments. For the north polar cap, a maximum for $R_{\text {top }}$ is reached 313 in 1993 with $-107 \mathrm{~W} \mathrm{~m}^{-2}$, with values as low as $-112 \mathrm{~W} \mathrm{~m}^{-2}$ occurring in 1981 and 2005.

314 MERRA TOA fluxes for the south polar cap have an irregular time series with a range between 315 minimum and maximum values of $4 \mathrm{~W} \mathrm{~m}^{-2}$. Over the Southern Ocean domain, a sharp change is 316 noted after 1998. This is likely due to the introduction of AMSU data to the observing system as 
317 noted earlier. Annual average values prior to 1998 are consistent with an average of $-81 \mathrm{~W} \mathrm{~m}^{-2}$.

318 For the period $1999-2005$ the MERRA average for the Southern Ocean is $-86 \mathrm{~W} \mathrm{~m}^{-2}$.

e. Surface fluxes

Figure 5 shows the annual average surface net heat flux from MERRA for both polar 322 regions. In the Northern Hemisphere, small negative values of between 0 and $-5 \mathrm{~W} \mathrm{~m}^{-2}$ are 323 found in a uniform field over nonglaciated land surfaces, which is consistent with subsurface 324 warming in recent years (Serreze et al., 2007). Over the central Arctic Ocean, MERRA net 325 surface flux values are positive as expected but are exceptionally large. Values greater than $32615 \mathrm{~W} \mathrm{~m}^{-2}$ are found in the central Arctic, and greater than $20 \mathrm{~W} \mathrm{~m}^{-2}$ in the approaches to the 327 North Atlantic. These annual values are extraordinary and likely not real istic. A comparison of 328 the averaged annual time series of monthly values with previous studies indicates largest 329 discrepancies occurring in summer months. The July $1979-2005$ net surface flux for MERRA is $330-68 \mathrm{~W} \mathrm{~m}^{-2}$ for the north polar cap as shown in Table 1. This compares with $-85 \mathrm{~W} \mathrm{~m}^{-2}$ for 331 ERA-40 (Serreze et al., 2007) and $-86 \mathrm{~W} \mathrm{~m}^{-2}$ for JRA-25 (Porter et al., 2010). Similar 332 differences are found betwen MERRA and contemporary reanalyses as shown in Table 2. For 333 the concurrent 1989-2005 averaging period, the July net surface flux for the north polar cap is $334-87 \mathrm{~W} \mathrm{~m}^{-2}$ for the CFSR and $-78 \mathrm{~W} \mathrm{~m}^{-2}$ for ERA-I. Discrepancies in the surface flux fields are eval uated using observations from the Surface 336 Heat Budget of the A rctic ice camp field study in the Beaufort Sea in October 1997 to October 3371998 (SHEBA; Uttal et al., 2002). MERRA surface flux values are compared with a compilation 338 of observed SHEBA radiative and turbulent flux measurements by Duynkerke and de Roode 339 (2001). Comparisons are made using the nearest MERRA grid point to the reported hourly drift 
340 camp position. For this data source, SHEBA latent heat flux observations were limited and are

341 not considered. Using the remaining energy budget components, a net flux comparison indicates

342 a positive (upward) bias in MERRA of $18 \mathrm{~W} \mathrm{~m}^{-2}$ for the months October to April, $-1 \mathrm{~W} \mathrm{~m}^{-2}$ for

343 May, and small positive biases for the following summer months.

344 There are three fundamental results of the comparison. As shown in Fig. 6, substantial

345 differences in the upwelling shortwave radiative flux result from an overly simplistic

346 representation of sea ice properties. Sea ice albedo is set to a fixed value of 0.60 for MERRA.

347 The surface observed using SHEBA tower measurements has a much higher albedo in

348 springtime, with monthly averages of 0.83 in March, April, and May, and 0.74 in June. A part

349 from the tower flux measurements, a line of surface al bedo observations made during SHEBA

350 provide a range of values that are dependent on the surface ice conditions. The average of these

351 surface observations is shown in Fig. 6 for June to September 1998. Albedos from tower

352 measurements in May 1998 are consistent with area-averaged surface and ai rcraft observations.

353 For example, Curry et al. (2001) note that albedo for A pril and May at the SHEBA site averaged

3540.84 , that the melt season lasted from late May to mid August, and that winter-spring albedo

355 val ues were again reached in late September. This difference with observed al bedo contributes to

356 an underesti mate in the upwelling shortwave flux in MERRA of $55 \mathrm{~W} \mathrm{~m}^{-2}$ in April, $80 \mathrm{~W} \mathrm{~m}^{-2}$ in

357 May, and $56 \mathrm{~W} \mathrm{~m}^{-2}$ in June. In late summer, the observed surface al bedo is degraded by melting

358 and becomes comparable to the MERRA value. In late autumn, freezing and the introduction of

359 solid precipitation again produces surface al bedo differences between MERRA and observation,

360 however the incoming solar flux is reduced and the impact on the upwelling shortwave is less

361 consequential. The difference with observation in the upwelling shortwave radiative flux for

362 May is the largest of any monthly budget component. 
The second result is a response in other MERRA surface energy budget terms in May to

364 the al bedo bias. Surface temperatures over ice in MERRA are determined via energy bal ance,

365 and the underestimate of the surface al bedo results in a perceived increased absorption of solar

366 energy and a surface warming. This likely results in the springtime MERRA sensible heat flux

367 bias, which is found to be $16 \mathrm{~W} \mathrm{~m}^{-2}$ in May. Other than the April, May, and June period, the

368 MERRA sensible heat flux difference with SHEBA observations is only $2 \mathrm{~W} \mathrm{~m}^{-2}$. An intriguing

369 finding is a springtime negative bias with SHEBA observations in the downwelling shortwave

370 radiative flux. The MERRA downwelling shortwave is underestimated by $36 \mathrm{~W} \mathrm{~m}^{-2}$ in April,

$37137 \mathrm{~W} \mathrm{~m}^{-2}$ in May and $25 \mathrm{~W} \mathrm{~m}^{-2}$ in June. In other months this difference is about $1 \mathrm{~W} \mathrm{~m}^{-2}$. This

372 bias is likely associated with general deficiencies in the representation of cloud properties. From

373 the seasonal timing of the bias, however, it is speculated that a portion of the amount is due to a

374 redistribution of cloudiness in the atmospheric column resulting from anomal ous surface

375 warming. The large May bias in upwelling shortwave radiation is then compensated for by biases

376 in other fluxes to produce the surface net energy flux bias of $-1 \mathrm{~W} \mathrm{~m}^{-2}$.

377 Shown in Fig. 7 is the time series of hourly near-surface air temperature in comparison to

378 the observed time series from SHEBA for the period 1 February to 30 June,1998. A temperature

379 bias in spring is readily apparent, with a difference of greater than $3.5^{\circ} \mathrm{C}$ in April and May before

380 the freezing value is reached in early June. In particular, the period 19 April to 10 May shows an

381 average bias of $6.1^{\circ} \mathrm{C}$ in MERRA. For daily averages, however, there is a good correlation

382 between MERRA and observation for the period shown $(r=0.95)$. It may be seen in the time

383 series of hourly values shown Fig. 7 that the diurnal cycle in MERRA temperature has an

384 amplitude between 2 and $10^{\circ} \mathrm{C}$, which begins abruptly on 28 March and continues unabated until

385 the freezing point is reached in June. The observed SHEBA diurnal cycle has a si milar 
386 amplitude, however the cycle is not as regular as in MERRA and there are periods of

387 considerable interruption, perhaps due to synoptic variability. These differences are suggestive of

388 difficulties in MERRA boundary layer parameterizations. Springtime air temperature biases are

389 found at Arctic station locations as well. For example, a comparison with Sachs Harbor $\left(72^{\circ} \mathrm{N}\right.$,

$390125^{\circ} \mathrm{W}$ ) over the period $1979-2005$ indicates an average of $4.9^{\circ} \mathrm{C}$ difference for A pril but only

$3911.9^{\circ} \mathrm{C}$ for the months August through March. A comparison with Barrow $\left(71^{\circ} \mathrm{N}, 157^{\circ} \mathrm{W}\right)$

392 similarly indicates an average bias in MERRA of $3.6^{\circ} \mathrm{C}$ for the spring months of March, A pril,

393 and May and $0.9^{\circ} \mathrm{C}$ for other months. But as shown in Fig. 8, MERRA performs well in a

394 comparison of monthly anomalies. The correlation between temperature anomalies at Barrow

395 and Jan Mayan $\left(71^{\circ} \mathrm{N}, 9^{\circ} \mathrm{W}\right)$ is 0.99 for both stations. The time series shown in Fig. 8 contain

396 observations that cover the entire time period. Other stations in the Arctic with shorter and/or

397 interrupted records compare similarly well.

398 The third result from the comparison with SHEBA is a negative bias in the downwelling

399 longwave radiative flux throughout the year of $12 \mathrm{~W} \mathrm{~m}^{-2}$. This quantity leads to the overall

400 positive bias in the net surface flux for summer, autumn, and winter months. As with the

401 springtime downwelling shortwave radiative flux bias, an inadequate representation of cloud

402 properties is implied. To eval uate this further, comparisons were made between MERRA and

403 SHEBA hourly microwave radiometer retrievals over the period 5 December 1997 to

4049 September 1998. More than 5000 observations were made over the period. Retrievals of

405 precipitable water compare remarkably well to MERRA val ues as seen in Fig. 9a, although

406 differences are apparent for small quantities in winter. For monthly intervals, the correlation

407 between MERRA and the hourly microwave radiometer precipitable water retrievals ranges from

$408 r=0.87$ in December 1997 to $r=0.96$ in May 1998. A consistent bias of $0.6 \mathrm{~mm}$ in monthly 
409 averages is found, which amounts to 31 percent of the observed average for January but only 4103 percent for July. In contrast, the comparison to retrieved liquid water content shown in Fig. 9b

411 is less favorable. Cloud liquid water from the SHEBA microwave radiometer ranges from an

412 average of $0.017 \mathrm{~mm}$ in January 1997 to $0.106 \mathrm{~mm}$ in August 1998. Typical MERRA values are

413 about 45 percent of the microwave radiometer amounts. Although large discrepancies have been

414 noted between the SHEBA microwave radiometer values for liquid water path and simultaneous

415 aircraft measurements (Lin et al., 2001), the differences between MERRA and SHEBA values

416 exceed 50 percent. Additionally, the correlations of hourly liquid water path val ues with

417 MERRA over monthly time intervals are low and range from $r=0.14$ in April 1998 to $r=0.55$ in

418 January 1998. The presence or absence of cloud liquid water significantly alters the downwelling

419 longwave radi ative flux. An underestimate of cloud liquid water in MERRA is qual itatively

420 consistent with differences in the surface net flux with observation.

421 Comparisons with MERRA for the Arctic are also conducted using the CFSR and ERA-I

422 reanal yses. Using monthly values co-located with the SHEBA ice drift camp, it is noted that

423 surface albedo varies seasonally and interannually in both CFSR and ERA-I. In agreement with

424 the SHEBA time series, both CFSR and ERA-I have albedos greater than 0.8 for April 1998, and

425 val ues decrease with the onset of the summer melt season. This decrease occurs more rapidly in

426 both CFSR and ERA-I than for tower observations, but is within the lower range given by

427 SHEBA line albedo measurements. The June 1998 al bedo is 0.59 for MERRA, 0.65 for CFSR,

4280.69 for ERA-I, 0.74 for the SHEBA tower observation, and 0.62 for the line observation. All

429 three reanalyses underestimate the downwelling longwave radiative flux over winter months in

430 comparison to SHEBA. For the period October 1997 to May 1998, this flux is underestimated by

$4315 \mathrm{~W} \mathrm{~m}^{-2}$ in ERA-I and $18 \mathrm{~W} \mathrm{~m}^{-2}$ in CFSR. Finally, the November 1997 to March 1998 average 
432 sensible heat flux observed at SHEBA is less than $1 \mathrm{~W} \mathrm{~m}^{-2}$. This compares with $3 \mathrm{~W} \mathrm{~m}^{-2}$ in

433 MERRA, $-7 \mathrm{~W} \mathrm{~m}^{-2}$ in ERA-I, and $-21 \mathrm{~W} \mathrm{~m}^{-2}$ in CFSR.

434 Turning to the Southern Hemisphere, the annual average net surface heat flux for the

435 south polar cap is shown in Fig. 5b. Of immediate concern is the anomal ous non-zero field over

436 Antarctica, which is shared by the major ice sheets in both polar regions. Over grounded ice, the

437 MERRA subsurface energy flux is determined in the GEOS- 5 model by the prognostic

438 temperature for a $7 \mathrm{~cm}$ (water-equival ent) surface ice layer and a "deep" layer temperature at $2 \mathrm{~m}$

439 depth that is fixed at $230^{\circ} \mathrm{K}$. Thus, the location of the zero value contour in Fig. $5 \mathrm{~b}$ exactly

440 matches the annual-average $230^{\circ} \mathrm{K}$ surface temperature isotherm. Observations from automatic

441 weather stations indicate that annual mean subsurface conductive heat fluxes are not significant

442 (e.g., Reijmer and Oerlemans, 2002), and annual surface energy flux patterns in MERRA over

443 Antactica (as well as Greenland) are erroneous.

444 The pattern in the MERRA annual surface net energy flux in Antarctica is manifest as a 445 complementary distribution of downward (negative) turbulent and upward (positive) radiative 446 fluxes that are not balanced. MERRA annual mean latent heating exceeds $5 \mathrm{~W} \mathrm{~m}^{-2}$ only along 447 the East Antarctic coast in selected locations, and averages less than $1 \mathrm{~W} \mathrm{~m}^{-2}$ for the total 448 grounded ice sheet area. The annual averaged sensible heat flux over the ice sheet is uniformly 449 negative and is approximately contour-parallel with topography, with magnitudes greater than $450(-) 60 \mathrm{~W} \mathrm{~m}^{-2}$ along the East Antarctic coastal escarpment decreasing to less than (-)10 $\mathrm{W} \mathrm{m}^{-2}$ 451 over the central plateau. The annual mean net radiative flux field in MERRA is spatially more 452 uniform with values ranging from (+)25 to $35 \mathrm{~W} \mathrm{~m}^{-2}$ for East Antarctica, and smaller positive 453 values over West Antarctica. This results in the imbal ances in the net surface heat flux as shown. 454 Over the interior plateau, net flux values are as large as $+15 \mathrm{~W} \mathrm{~m}^{-2}$ while the net amounts at 
455 lower elevations are negative and are less than $-30 \mathrm{~W} \mathrm{~m}^{-2}$ over the East Antarctic coastal 456 escarpment. These errors in the net surface flux have rel ation to near-surface temperature biases. 457 As shown in Fig. 10, there is a considerable wintertime warm bias of $5^{\circ} \mathrm{C}$ at Amundsen-Scott $458\left(90^{\circ} \mathrm{S}\right)$, while a summer cold bias of $5^{\circ} \mathrm{C}$ is found at Scott Base $\left(78^{\circ} \mathrm{S}, 167^{\circ} \mathrm{E}\right)$. Visual 459 comparison with satellite-derived surface air temperatures in Comiso (2000) indicates that a 460 summer cold bias extends over the embayment regions.

461 Comparisons of surface energy budget components are made with Antarctic station 462 values compiled by King and Turner (1997). Val ues compiled by King and Turner (1997) reflect 463 studies of opportunity and do not account for interannual variability. For the sensible heat flux, 464 MERRA averages at Mizuho $\left(71^{\circ} \mathrm{S}, 44^{\circ} \mathrm{E}\right)$ of $-47 \mathrm{~W} \mathrm{~m}^{-2}$ in July and $-19 \mathrm{~W} \mathrm{~m}^{-2}$ in December 465 compare with observational values of -37 and $-25 \mathrm{~W} \mathrm{~m}^{-2}$ for July and December, respectively 466 (Ohata et al., 1985). At South Pole, differences in seasonal values of the sensible heat flux are 467 largest in spring and summer. The December-January-February sensible flux average from 468 MERRA is $-3 \mathrm{~W} \mathrm{~m}^{-2}$ and $-22 \mathrm{~W} \mathrm{~m}^{-2}$ in observation (Carroll, 1982). This contributes to a 469 difference of $9 \mathrm{~W} \mathrm{~m}^{-2}$ in the annual average.

470 Differences between MERRA and available observations are also associated with the net 471 radiative flux. At Halley $\left(76^{\circ} \mathrm{S}, 26^{\circ} \mathrm{W}\right)$, the annual average net radiative flux for MERRA of

$47213 \mathrm{~W} \mathrm{~m}^{-2}$ approximates the observational values of $9.8 \mathrm{~W} \mathrm{~m}^{-2}$, however seasonal differences are 473 as large as $10 \mathrm{~W} \mathrm{~m}^{-2}$ in winter. At South Pole, the annual net radiative flux of $19 \mathrm{~W} \mathrm{~m}^{-2}$ matches 474 the observation of Carroll (1982), however seasonal differences are large. In winter, the net 475 radiative surface cooling of $36 \mathrm{~W} \mathrm{~m}^{-2}$ exceeds the observed value of $21 \mathrm{~W} \mathrm{~m}^{-2}$. In summer, the 476 MERRA radiative flux value of $-7 \mathrm{~W} \mathrm{~m}^{-2}$ differs from the Carroll (1982) value of $+18 \mathrm{~W} \mathrm{~m}^{-2}$. 
The surface radiative flux differences at South Pole are further examined using the

478 observations of Dutton et al. (1989), who recorded daily mean radiative flux components from

479 April 1986 until February 1988. Over this period, the surface net radiative flux for both MERRA

480 and observation is positive for most of the year but becomes negative in summer months as seen

481 in Fig. 11. Over the 22 month period, the downwelling longwave radiative flux is consistently

482 less than observation by an average $24 \mathrm{~W} \mathrm{~m}^{-2}$. This difference is apparent in the comparison of

483 daily values in Fig. 11. Large biases are al so found in the MERRA net shortwave radiative flux

484 in spring and summer. For the month of January, the net downward shortwave flux is

485 overestimated by $20 \mathrm{~W} \mathrm{~m}^{-2}$ in 1987 , and by $23 \mathrm{~W} \mathrm{~m}^{-2}$ in 1988 . A minor part of the shortwave

486 bias is associated with the MERRA surface al bedo, which is fixed over land ice at 0.775 .

487 Observed monthly averages at South Pole indicate an al bedo of between 0.80 and 0.89 . These

488 differences in the shortwave flux partially cancel the downwelling longwave underestimate in

489 summer. It may be seen from Fig. 11 that some of the day-to-day variability in the downwelling

490 longwave radiative flux is reproduced in MERRA. By subtracting a 30-day running mean from

491 each time series to remove the annual cycle, the two curves have a correlation of 0.70 .

492 Table 2 presents a comparison of net surface flux values for the south polar cap. Both the

493 ERA-I and the CFSR correctly depict a near-zero annual net flux field over the Antarctic ice

494 sheet, while regions of opposite sign in MERRA $F_{s f c}$ fortuitously cancel. Monthly values of

495 surface radiative flux components from CFSR and ERA-I are compared to 1986-1988 values

496 from Dutton et al. (1989) for the South Pole. The ERA-I collection begins in 1989, so 1989-2005

497 averages were used. In general, the monthly net surface radiative fluxes of the three reanalyses

498 are more similar to each other than to observation. The net upward radiative flux is

499 overestimated by $18 \mathrm{~W} \mathrm{~m}^{-2}$ for MERRA, $16 \mathrm{~W} \mathrm{~m}^{-2}$ for ERA-I, and $20 \mathrm{~W} \mathrm{~m}^{-2}$ for CFSR. Similar 
500 to MERRA, a large part of the ERA-I difference is due to an underestimate of the downwelling

501 longwave component. For the annual average, the ERA-I downwelling longwave flux is

502 underestimated by $15 \mathrm{~W} \mathrm{~m}^{-2}$. For the CFSR, the upwelling longwave flux is overestimated for

503 winter months March to September by $21 \mathrm{~W} \mathrm{~m}^{-2}$, and this provides a significant contribution to

504 annual net flux differences. Both ERA-I and CFSR have variable surface albedos at South Pole,

505 however the ERA-I val ue approximates the MERRA fixed val ue, while the CFSR value averages

5060.84 during summer months.

507 The spatial patterns of Fig. $5 \mathrm{~b}$ are of interest over the Southern Ocean. In the annual

508 mean, MERRA indicates a net loss of energy from the ocean to the atmosphere south of $60^{\circ} \mathrm{S}$

509 which increases in magnitude near the continent. Farther north there is a marked asymmetry

510 within the $50^{\circ} \mathrm{S}-60^{\circ} \mathrm{S}$ zone, with net energy loss from the ocean to the atmosphere in the Pacific

511 sector and energy gains el sewhere. Embedded within the Pacific sector are two regions of net

512 energy gain from the atmosphere to the ocean which correspond to meanderings of the Antarctic

513 Polar Front- as it crosses the Southeast Indian Ridge near $145^{\circ} \mathrm{E}$, and the Pacific-Antarctic Ridge

514 near $145^{\circ} \mathrm{W}$ (e.g., Moore et al., 1999). Josey (2009) noted the zonal asymmetry in the net surface

515 heat flux in NCEP and ECMWF reanal yses but found that coupled models produce a more

516 zonally uniform field. Josey (2009) concluded that the sign of annual mean surface heat

517 exchange over much of the region is not known. The net surface flux from ERA-I and CFSR

518 reanal yses in Southern high latitudes differ with MERRA. The coastal zone of heat loss from the

519 ocean to the atmosphere in both the ERA-I and CFSR is more closely confined near the continent

520 than in MERRA. Similar to MERRA, the ERA-I indicates an annual mean net positive energy

521 flux from the ocean to the atmosphere in the Pacific Ocean sector of the $50^{\circ} \mathrm{S}-60^{\circ} \mathrm{S}$ zone, while 
522 the CFSR indicates negative values between 0 and $-15 \mathrm{~W} \mathrm{~m}^{-2}$ that are smaller in magnitude than

523 for the rest of the zone.

524 The annual cycle of the net surface flux for the Southern Ocean is shown in Fig. 3c.

525 Using ECMWF operational analyses overlapping the period of the ERBE study, Okada and

526 Yamanouchi (2002) examined the atmospheric energy budget for the region bounded by $60^{\circ} \mathrm{S}$

527 and $70^{\circ} \mathrm{S}$. Okada and Yamanouchi estimated the surface energy budget as the residual using

528 TOA ERBE radiation and analyses divergence terms. A seasonal asymmetry in the net surface

529 flux was highlighted, which was found to abruptly peak in May with a maximum value of

$530116 \mathrm{~W} \mathrm{~m}^{-2}$. Okada and Yamanouchi (2002) attributed this asymmetry to the latent heat rel ease

531 resulting from sea ice formation. As seen in Fig. 3c, the MERRA surface energy flux over the

532 Southern Ocean sea ice domain is al so asymmetric and peaks in May at $98 \mathrm{~W} \mathrm{~m}^{-2}$, however the

533 maximum is not as striking as was found for the ECMWF analyses. In examining the autumnal

534 surface turbulent fluxes in MERRA, it is found that the total latent heat flux is a maximum for

535 the domain in April with $33 \mathrm{~W} \mathrm{~m}^{-2}$. The latent heat flux then diminished over ice covered winter

536 months, with a second maxima in November of $28 \mathrm{~W} \mathrm{~m}^{-2}$. The MERRA sensible heat flux

537 reaches its annual maximum in May of $21 \mathrm{~W} \mathrm{~m}^{-2}$ and generally reflects the shape of surface net

538 flux. The asymmetry in the annual cycle for the MERRA net surface flux as shown in Fig. 3c is

539 principally due to seasonal changes in the sensible heat flux. In reanal yses, sea ice cover is

540 prescribed from observational fields. The latent heat flux arising from ice formation is manifest

541 as the net conductive flux at the atmosphere-ice interface. In this context, MERRA and the

542 results of Okada and Yamanouchi (2002) are broadly consistent. 


\section{Summary and Discussion}

MERRA reproduces the basic patterns of energy flow in the polar atmosphere as they are

546 known. As shown in Fig. 3, the polar regions are marked by a convergence of energy from lower

547 latitudes for all months, and a loss of energy at the top of the atmosphere for the most of the year.

548 In the Arctic, reductions in the TOA shortwave radiative flux in autumn produce a negative

549 tendency in the atmospheric column total energy throughout the period August through January,

550 which is moderated by contributions from the net surface flux and increased energy transport

551 from lower latitudes in winter (Serreze et al., 2007). In the Antarctic, this seasonal progression is

552 less sinusoidal, with the net TOA radiative flux remaining negative throughout the year, and an

553 extended winter period in the energy budget components extending from April to September.

554 Despite reproducing these essential components, MERRA energy budgets for the Arctic

555 and Antarctic contain substantial errors owing to overly simplistic physical parameterizations,

556 including sea ice albedo, the surface heat budget over permanent land ice, and cloud radiative

557 properties. Difficulties in MERRA with sea ice characteristics are not dissi milar from those

558 described in Bretherton et al. (2000) for ECMWF analyses produced during SHEBA, and indeed

559 the discrepancies in surface shortwave radiative fluxes are si milar. Spring is a critical period for

560 evaluation of surface flux fields in the Arctic, and differences between MERRA shortwave

561 surface radiative fluxes with observation are most prominent in May. Over the data sparse

562 Southern Ocean, discontinuities in the time series of TOA radiative fluxes coincide with the

563 introduction of AMSU satellite data in November 1998 and are therefore spurious. Elsewhere,

564 interannual variability of the analysis increments term $A N A_{(E)}$ is large but not as easily linked to

565 changes in the observing system. Additional characterization of analysis increments, including 
566 their vertical distribution, and MERRA cloud properties are conspicuous points for further 567 evaluation.

MERRA nevertheless compares favorably to previous studies of energy budget

569 components produced from state and dynamical variables. These vertical integrals are pre

570 computed quantities in MERRA, and are not readily avai lable from contemporary reanalyses.

571 Atmospheric energy convergence and the spatial distribution of transport along the $70^{\circ}$ parallel

572 compare closely with previous studies in the Northern Hemisphere, while estimates for the south

573 polar cap are qualitatively similar but may al so been seen as an update to studies based on earlier

574 analyses. The total atmospheric energy tendency in polar regions al so compares favorably to

575 previous studies.

576 Credible estimates of the atmospheric energy budget in polar regions continue to be a

577 significant challenge due to changes in the observing system and complex energy feedback

578 mechanisms that are associated with the high latitudes. Evaluation using both representative

579 point location observations and previous area-averaged estimates such as those used in this study

580 are valuable for providing a straightforward appraisal of new reanalyses. The MERRA system is

581 an important product due to its al ternative construction, including a non-spectral background

582 model and its emphasis on NASA satel lite products. An important concept used in MERRA is

583 the employment of analysis increments for identifying differences between observations and the

584 background analysis system. Inconsistencies in atmospheric budgets are quantified in the

585 analysis increments, which is one means of measuring uncertainty. ERA-I and CFSR reanalyses

586 are found to utilize seasonal variations in sea ice al bedo and have realistic annual mean surface

587 heat fluxes over ice sheets. However these collections are al so found to have significant

588 discrepancies with observed surface and TOA energy fluxes. In particular, sensible heat fluxes 
589 from CFSR are large in comparison to SHEBA observations, while all three reanal yses 590 overestimate the annual surface net radiative flux at South Pole by 16 to $20 \mathrm{~W} \mathrm{~m}^{-2}$. These 591 disagreements underscore the challenge of the high latitude energy budget problem.

592 A general criticism of reanalyses is that they are produced with the intent of providing the 593 best representation of conditions for a given time without consideration for the impact of 594 heterogeneous observations on temporal variability (Thorne and Vose, 2010). This intent 595 nevertheless has practical, scientific application. Additionally, reanal yses may be seen as part of 596 a spectrum of products for climate study ranging from heterogeneous observations to model 597 simulations, which include AMIP fields and sparse data reanal yses (e.g., Compo et al., 2006). As 598 part of that continuum, the analysis increments in MERRA provides a quantification of 599 differences between observations and the background system. Changes in the spatial and 600 temporal variability of the analysis increments imply changes to the observing system, which 601 should be carefully treated in evaluating time series. MERRA is a valuable record for examining 602 the polar atmosphere when these cautions are exercised.

Acknowledgments. Data from the Surface Heat Budget of the Arctic Ocean experiment

605 (SHEBA) were obtained from the University of Washington Department of Atmospheric

606 Sciences, Seattle, Washington. Reference Antarctic Data for Environmental Research

607 (READER) is a project of the Scientific Committee on Antarctic Research (SCAR) and were

608 obtained from British Antarctic Survey (BAS), Cambridge, United Kingdom. Arctic station

609 values from the Integrated Surface Database (ISD) and the Integrated Rawinsonde Global

610 Rawinsonde Archive (IGRA) were obtained from the National Climate Data Center, Asheville, 611 North Carolina. The ERA-I collection was obtained from the ECMWF Data Server. The CFSR 
612 collection was obtained from the National Climate Data Center. This study was funded by grants

613 from the NASA Modeling Analysis and Prediction Program (MAP) and the NASA Energy and

614 Water cycle Study (NEWS) to the second author.

615

616

617

618

619

620

621

622

623

624

625

626

627

628

629

630

631

632

633

634

635

636

637

638

639

640

641

642

643

644

645

646

647

648

649

\section{APPENDIX}

Representation of the Atmospheric Energy Budget Using MERRA Variables

The following MERRA variables are given as follows.

DQVDT_DYN Vertically integrated water vapor tendency for dynamics

DQVDT_PHY

$D Q V D T \_A N A$

$D Q I D T+D Y N$

$D Q I D T+P H Y$

DQIDT_ANA

$D Q V D T_{-} C H M$

DQVDT_FIL

$D Q I D T_{-} F I L$

$D K D T+D Y N$

$D K D T_{-} P H Y$

$D K D T_{-} A N A$

$D H D T+D Y N$

$D H D T_{-} P H Y$

$D H D T \_A N A$

$D P D T \_D Y N$

$D P D T_{-} P H Y$

$D P D T_{-} A N A$

CONVKE

CONVCPT

CONVPHI

SWTNT

SWGNT

LWTUP

LWGNT

EFLUX

HFLUX

PRECSN
Vertically integrated water vapor tendency for physics

Vertically integrated water vapor tendency for analysis

Vertically integrated ice water tendency for dynamics

Vertically integrated ice water tendency for physics

Vertically integrated ice water tendency for analysis

Vertically integrated water tendency for chemistry

Artificial "filling" of water vapor

Artificial "filling" of frozen water

Vertically integrated kinetic energy tendency for dynamics $\mathrm{W} \mathrm{m}^{-2}$

Vertically integrated kinetic energy tendency for physics

Vertically integrated kinetic energy tendency for analysis

Vertically integrated $c_{P} \cdot T_{v}$ tendency for dynamics

Vertically integrated $c_{P} \cdot T_{v}$ tendency for physics

Vertically integrated $c_{P} \cdot T_{v}$ tendency for analysis

Potential energy tendency for dynamics

Potential energy tendency for physics

Potential energy tendency for analysis

Vertically integrated convergence of kinetic energy

Vertically integrated convergence of virtual enthalpy

Vertically integrated convergence of geopotential

TOA outgoing shortwave flux

Surface net downward shortwave flux

Upward TOA longwave flux

Net downward longwave flux at the surface

Latent heat flux (positive upward)

Sensible heat flux (positive upward)

Frozen precipitation at the surface $\mathrm{kg} \mathrm{m}^{-2} \mathrm{~s}^{-1}$

$\mathrm{kg} \mathrm{m}^{-2} \mathrm{~s}^{-1}$

$\mathrm{kg} \mathrm{m}^{-2} \mathrm{~s}^{-1}$

$\mathrm{kg} \mathrm{m}^{-2} \mathrm{~s}^{-1}$

$\mathrm{kg} \mathrm{m}^{-2} \mathrm{~s}^{-1}$

$\mathrm{kg} \mathrm{m}^{-2} \mathrm{~s}^{-1}$

$\mathrm{kg} \mathrm{m}^{-2} \mathrm{~s}^{-1}$

$\mathrm{kg} \mathrm{m}^{-2} \mathrm{~s}^{-1}$

$\mathrm{kg} \mathrm{m}^{-2} \mathrm{~s}^{-1}$

$W \mathrm{~m}^{-2}$

$W m^{-2}$

$W \mathrm{~m}^{-2}$

$W \mathrm{~m}^{-2}$

$W \mathrm{~m}^{-2}$

$W \mathrm{~m}^{-2}$

$W \mathrm{~m}^{-2}$

$W \mathrm{~m}^{-2}$

$W \mathrm{~m}^{-2}$

$W \mathrm{~m}^{-2}$

$\mathrm{W} \mathrm{m} \mathrm{m}^{-2}$

$W \mathrm{~m}^{-2}$

$W \mathrm{~m}^{-2}$

$W \mathrm{~m}^{-2}$

$W \mathrm{~m}^{-2}$

$\mathrm{W} \mathrm{\textrm {m } ^ { - 2 }}$

$W \mathrm{~m}^{-2}$

$\mathrm{kg} \mathrm{m}^{-2} \mathrm{~s}^{-1}$ 
A tendency may be expressed as the sum of dynamics, physics, and analysis variables. For example, the tendency of vertically integrated water vapor (precipitable water) is expressed using MERRA variables as follows.

$$
\frac{\partial W_{(v)}}{\partial t}:=D Q V D T_{-} D Y N+D Q V D T_{-} P H Y+D Q V D T_{-} A N A
$$

Equation (2) is represented as follows.

660

661

662

663

664

665

666

667

668

669

670

671

672

673

674

675

676

677

678

679

680

681

682

683

$$
\begin{aligned}
\frac{\partial A_{E}}{\partial t}:= & L_{v} \cdot\left(D Q V D T_{-} D Y N+D Q V D T_{-} P H Y+D Q V D T_{-} A N A\right) \\
i \quad & L_{f} \cdot\left(D Q I D T_{-} D Y N+D Q I D T_{-} P H Y+D Q I D T_{-} A N A\right) \\
& +D H D T_{-} D Y N+D H D T_{-} P H Y+D H D T_{-} A N A \\
& +D P D T_{-} D Y N+D P D T_{-} P H Y+D P D T_{-} A N A \\
& +D K D T \_D Y N+D K D T_{-} P H Y+D K D T \_A N A
\end{aligned}
$$

Equation (3) is represented as:

$$
\begin{gathered}
\nabla \cdot \tilde{\mathbf{F}}_{A}:=-\left(L_{v} \cdot D Q V D T \_D Y N-L_{f} \cdot D Q I D T \_D Y N\right. \\
+C O N V K E+C O N V C P T+C O N V P H I)
\end{gathered}
$$

Equations (4) and (5) are represented as follows.

$$
\begin{gathered}
R_{\text {top }}+F_{s f}:=(S W T N T-L W T U P) i \quad(S W G N T+L W G N T) \\
+E F L U X+H F L U X+L_{f} \cdot P R E C S N
\end{gathered}
$$

The contribution of spurious residual s in the energy term is represented as:

$$
\begin{gathered}
Q_{N U M}:=i \text { DKDT_DYN + CONVKE + CONVPHI } \\
+ \text { DKDT_GEN } i \text { DPDT_DYN } i \text { TEFIXER }
\end{gathered}
$$

The remainder of equation (1) is given as follows.

$$
\begin{aligned}
& \left.L_{v} \frac{\partial \boldsymbol{W}_{v}}{\partial \boldsymbol{t}}\right|_{C H M}+\left.\left[\boldsymbol{L}_{v} \frac{\partial \boldsymbol{W}_{v}}{\partial \boldsymbol{t}}-L_{f} \frac{\partial \boldsymbol{W}_{i}}{\partial \boldsymbol{t}}\right]\right|_{F I L}+\boldsymbol{A N} A_{(E)}:= \\
& L_{v} \cdot D Q V D T_{-} C H M+\left(L_{v} \cdot D Q V D T_{-} F I L-L_{f} \cdot D Q I D T_{-} F I L\right) \\
& +\left(L_{v} \cdot D Q V D T \_A N A i \quad L_{f} \cdot D Q I D T+A N A+D H D T \_A N A\right. \\
& \left.+D K D T \_A N A+D P D T \_A N A\right)
\end{aligned}
$$


685

Barkstrom, B.R., 1984: The Earth Radiation Budget Experiment (ERBE). Bull. Amer. Meteor. Soc., 65, 1170-1185.

Bloom, S., L. Takacs, A. DaSilva, and D. Ledvina, 1996: Data assimilation using incremental anal ysis updates. Mon. Wea. Rev., 124, 1256-1271.

Bosilovich, M.G., F.R. Robertson, and J. Chen, 2010: Global energy and water budgets in MERRA. J. Climate (in review).

Bretherton, C.S., S.R. de Roode, C. Jakob, E.L. Andreas, J. Intrieri, and R.E. Moritz, and P.O.G. Persson, 2000: A comparison of the ECMWF forecast model with observations over the annual cycle at SHEBA. Unpublished manuscript, 46 pp. (Available from http://citeseerx.ist.psu.edu/viewdoc/download?doi=10.1.1.36.9608\& rep=rep1\& type=pdf). Briegleb, B.P, and D.H. Bromwich, 1998: Polar climate simulations of the NCAR CCM3. J. Climate, 11, 1270-1286.

Carroll, J.J., 1982: Long-term means and short-term variability of the surface energy balance components at South Pole. J. Geophys. Res., 87, 4277-4286.

Comiso, J.C., 2000: Variability and trends in Antarctic surface temperatures from in situ and satellite infrared measurements. J. Climate, 13, 1674-1696.

Compo, G.P., J.S. Whitaker, and P.D. Sardeshmukh, 2006: Feasibility of a 100-year reanal ysis using only surface pressure data. Bull. Amer. Meteor. Soc., 87, 175-190.

Cullather, R.I., and M.G. Bosilovich, 2010: The moisture budget of the polar atmosphere in MERRA. J. Climate, submitted.

Curry, J.A., J.L. Schramm, D.K. Perovich, and J.O. Pinto, 2001: Applications of SHEBA/FIRE data to evaluation of snow/ice al bedo parameterizations. J. Geophys. Res., 106, 15,34515,355 .

Duynkerke, P., and S. de Roode, 2001: Surface energy balance and turbulence characteristics observed at the SHEBA Ice Camp during FIRE III. J. Geophys. Res., 106, 15313-15322.

Dutton, E.G., R.S. Stone, J.J. DeLuisi, 1989: South Pole surface radiation balance measurements, April 1986 to February 1988. NOAA ERL Air Resources Laboratory Data Report Series, 17, $49 \mathrm{pp}$.

Fasullo, J.T., and K.E. Trenberth, 2008: The annual cycle of the energy budget. Part I. Global mean and land-ocean exchanges. J. Climate, 21, 2297-2312.

Genthon, C., and G. Krinner, 1998: Convergence and disposal of energy and moisture on the Antarctic polar cap from ECMWF Reanal yses and Forecasts. J. Climate, 11, 1703-1716.

Gibson, J.K., P. Kållberg, S. Uppala, A. Hernandez, A. Nomura, and E. Serrano, 1997: ERA Description. ECMWF Reanal yis Project Report Series, No. 1, 72 pp. Josey, S.A., 2009: Southern Ocean air-sea flux climatologies and uncertainties. CLIVAR/CliC/SCAR Southern Ocean Region Implementation Panel 5th Meeting, 16-18 February 2009, Sydney, Australia (PowerPoint presentation) [Available from Climate Variability \& Predictability project (CLIVAR), World Climate Research Programme, http://www.clivar.org/organization/southern/sop5_talks.php]. 
Kalnay, E., M. Kanamitsu, R. Kistler, W. Collins, D. Deaven, L. Gandin, M. Iredell, S. Saha, G. White, J. Woollen, Y. Zhu, A. Leetmaa, R. Reynolds, M. Chelliah, W. Ebisuzaki, W.Higgins, J. Janowiak, K. C. Mo, C. Ropel ewski, J. Wang, R. Jenne, and D. Joseph, 1996: The

King, J.C., and J. Turner, 1997: Antarctic Meteorology and Climatology. Cambridge Univ. Press, United Kingdom, 409 pp.

Levitus, S., 1984: Annual cycle of temperature and heat storage in the world ocean. J. Phys. Ocean., 14, 727-746.

Lin, B., P. Minnis, A. Fan, J.A. Curry, and H. Gerber, 2001: Comparison of cloud liquid water paths derived from in situ and microwave radiometer data taken during the SHEBA/FIREACE. Geophys. Res. Lett., 28, 975-978.

Moore, J.K., M.R. A bbott, and J.G. Richman, 1999: Location and dynamics of the Antarctic Polar Front from satellite sea surface temperature data. J. Geophys. Res., 104, 3059-3073.

Nakamura, N., and A.H. Oort, 1988: A tmospheric heat budgets of the polar regions. J. Geophys. Res., 93, 9510-9524.

Ohata, T., N. Ishikawa, S. Kobayashi, and S. Kawaguchi, 1985: Heat balance at the snow surface in a katabatic wind zone, East Antarctica. Ann. Glaciol., 6, 174-177.

Okada, I., and T. Yamanouchi, 2002: Seasonal change of the atmospheric heat budget over the Southern Ocean from ECMWF and ERBE data. J. Climate, 15, 2527-2536.

Onogi, K., J. Tsutsui, H. Koide, M. Sakamoto, S. Kobayashi, H. Hatsushika, T. Matsumoto, N. Yamazaki, H. Kamahori, K. Takahashi, S. Kadokura, K. Wada, K. Kato, R. Oyama, T. Ose, N. Mannoji, and R. Taira, 2007: The JRA-25 reanalysis. J. Meteor. Soc. Japan, 85, 369-432. Oort, A.H., 1983: Global atmospheric circulation statistics, 1958-1973. NOAA Professional Paper No. 14, U.S. Government Printing Office, Washington, DC, 180 pp.+47 microfiches. Porter, D.F., J.J. Cassano, M.C. Serreze, and D.N. Kindig, 2010: New estimates of the largescale Arctic atmosphere energy budget. J. Geophys. Res., 115, D08108, doi:10.1029/2009JD012653.

Randall, D., J. Curry, D. Battisti, G. Flato, R. Grumbine, S. Hakkinen, D. Martinson, R. Preller, J. Walsh, and J. Weatherly, 1998: Status of and outlook for large-scale modeling of atmosphere-ice ocean interactions in the Arctic. Bull. Amer. Meteor. Soc., 79, 197-219.

Reijmer, C.H., and J. Oerlemans, 2002: Temporal and spatial variability of the surface energy balance in Dronning Maud Land, East Antarctica. J. Geophys. Res., 107, 4759, doi:10.1029/2000.JD000110.

Rienecker, M.M., M.J. Suarez, R. Todling, J. Bacmeister, L. Takacs, H.-C. Liu, W. Gu, M. Sienkiewicz, R.D. Koster, R. Gelaro, I. Stajner, and E. Nielsen, 2009: The GEOS-5 Data Assimilation System- Documentation of Versions 5.0.1, 5.1.0, and 5.2.0. Technical Report Series on Global Modeling and Data Assimilation, NASA/TM-2007-104606, M.J. Suarez, Ed., Vol. 27, 95 pp.

Rienecker, M.M., and coauthors, 2010: The NASA Modern Era Retrospective-Anal ysis for Research and A pplications (MERRA). J. Climate (in preparation). 
Saha, S., S. Moorthi, H.-L. Pan, X. Wu, J. Wang, S. Nadiga, P. Tripp, R. Kistler, J. Woollen, D. Behringer, H. Liu, D. Stokes, R. Grumbine, G. Gayno, J. Wang, Y.-T. Hou, H. Chuang, H.H. Juang, J. Sela, M. Iredell, R. Treadon, D. Kleist, P. Van Delst, D. Keyser, J. Derber, M. Ek, J. Meng, H. Wei, R. Yang, S. Lord, H. van den Dool, A. Kumar, W. Wang, C. Long, M. Chelliah, Y. Xue, B. Huang, J.-K. Schemm, W. Ebisuzaki, R. Lin, P. Xie, M. Chen, S. Zhou, W. Higgins, C.-Z. Zou, Q. Liu, Y. Chen, Y. Han, L. Cucurull, R.W. Reynolds, G. Rutledge,
and M. Goldberg, 2010: The NCEP Climate Forecast System Reanalysis. Bull. Amer. Meteor. Soc., submitted.

Serreze, M.C., A.P. Barrett, A.G. Slater, M. Steel e, J. Zhang, and K.E. Trenberth, 2007:

The large-scale energy budget of the Arctic. J. Geophys. Res., 112, D11122, doi:10.1029/2006.JD008230.

Simmons, A.J., S. Uppala, D. Dee, and S. Kobayashi, 2007: ERA-Interim: New ECMWF reanal ysis products from 1989 onwards. ECMWF Newsletter, 110, 25-35.

Thorne, P.W., and R.S. Vose, 2010: Reanalyses suitable for characterizing long-term trends. Are they really achievable? Bull. Amer. Meteor. Soc., 91, 353-361.

Trenberth, K.E., 1997: Using atmospheric budgets as a constraint on surface fluxes. J. Climate, 10, 2796-2809.

Uppala, S.M., P.W. Kål lberg, A.J. Simmons, U. Andrae, V. da Costa Bechtold, M. Fiorino, J.K. Gibson, J. Haseler, A. Hernandez, G.A. Kelly, X. Li, K. Onogi, S. Saarinen, N. Sokka, R.P. Allan, E. Andersson, K. Arpe, M.A. Bal maseda, A.C.M. Beljaars, L. van de Berg, J. Bidlot, N. Bormann, S. Caires, F. Chevallier, A. Dethof, M. Dragosavac, M. Fisher, M. Fuentes, S. Hagemann, E. Hólm, B.J. Hoskins, L. Isaksen, P.A.E.M. Janssen, R. Jenne, A.P. McNally, J.F. Mahfouf, J.-J. Morcrette, N.A. Rayner, R.W. Saunders, P. Simon, A. Sterl, K.E. Trenberth, A. Untch, D. Vasiljevic, P. Viterbo, and J. Woollen, 2005: The ERA-40 re-analysis. Quart. J. R. Meteorol. Soc., 131, 2961-3012.

Uttal, T., J.A. Curry, M.G. Mcphee, D.K. Perovich, R.E. Moritz, J.A. Maslanik, P.S. Guest, H.L. Stern, J.A. Moore, R. Turenne, A. Heiberg, M.C. Serreze, D.P. Wylie, O.G. Persson, C.A. Paulson, C. Halle, J.H. Morison, P.A. Wheeler, A. Makshtas, H. Welch, M.D. Shupe, J.M. Intrieri, K. Stamnes, R.W. Lindsey, R. Pinkel, W.S. Pegau, T.P. Stanton, and T.C. Grenfeld, 2002: Surface Heat Budget of the Arctic Ocean. Bull. Amer. Meteor. Soc., 83, 255-275. Wielicki, B.A., B.R. Barkstrom, E.F. Harrison, R.B. Lee, G.L. Smith, and J.E. Cooper, 1996: Clouds and the Earth's Radiant Energy System (CERES): An Earth Observing System experiment. Bull. Amer. Meteor. Soc., 77, 853-868. 


\section{List of Table Captions}

800 TABLE 1. Components of the MERRA atmospheric energy budget for regions defined in Fig. 1,

801 in $\mathrm{W} \mathrm{m}^{-2}$. The surface flux $F_{s f c}$ discounts latent heating from solid precipitation. The standard

802 deviation over the 1979-2005 time period is indicated in parentheses.

803

804 TABLE 2. MERRA, CFSR, and ERA-I 1989-2005 average TOA and surface energy flux values

805 for regions defined in Fig. 1, in $\mathrm{W} \mathrm{m}^{-2}$. The standard deviation over the time period is indicated

806 in parentheses.

807

808 List of Figure Captions

809 Figure 1. Regions of study for (a) the Northern Hemisphere and (b.) the Southern Hemisphere.

810 Bold line indicates the $70^{\circ}$ parallel. Continental areas are shaded gray.

811

812 FIGURE 2. Average MERRA analysis increments field for the atmospheric energy budget

813 (variable $A N A_{(E)}$ ) for (a.) the Northern Hemisphere and (b.) the Southern Hemisphere. The

814 contour interval is $20 \mathrm{~W} \mathrm{~m}^{-2}$. The zero contour is indicated with a solid black line.

815

816 FIGURE 3. Annual cycle of atmospheric energy budget components in MERRA for (a) north

817 polar cap, (b.) south polar cap, and (c.) the Southern Ocean domain, in W $\mathrm{m}^{-2}$. Bars indicate plus 818 and minus the standard deviation for the period 1979-2005. 
820 FiguRE 4. Average monthly meridional energy transport from MERRA (a) across $70^{\circ} \mathrm{N}$,

821 contoured every $5 \cdot 10^{9} \mathrm{~W} \mathrm{~m}^{-1}$, and (b.) $70^{\circ} \mathrm{S}$, contoured every $3 \cdot 10^{9} \mathrm{~W} \mathrm{~m}^{-1}$. Positive values

822 indicate northward transport.

823

824 FIGURE 5. Annual average net surface heat flux from MERRA (positive upwards). Contours are

825 plotted with an interval of $20 \mathrm{~W} \mathrm{~m}^{-2}$ and for the levels $-10,-5,0,5$, and $10 \mathrm{~W} \mathrm{~m}^{-2}$. The zero

826 contour is indicated with a solid black line.

827

828 FIGURE 6. Monthly averaged surface al bedo (gray) and upwelling shortwave radiative flux (dark)

829 for SHEBA observed (solid) and corresponding MERRA values (dashed) for October 1997 to

830 September 1998, in W $\mathrm{m}^{-2}$. "Tower" values are from downward-pointing pyranometer

831 measurements, while "line albedo" values are from surface measurements al ong a 300m line.

832

833 FIGURE 7. Near-surface hourly air temperature from SHEBA and corresponding values from

834 MERRA for the period 1 February 1998 to 30 June 1998, in degrees C.

835

836 FIGURE 8. Time series of monthly averaged near-surface station air temperature anomaly and

837 corresponding MERRA values for Barrow (left, $71^{\circ} \mathrm{N}, 157^{\circ} \mathrm{W}$ ) and Jan Mayen (right, $71^{\circ} \mathrm{N}$,

$\left.8389^{\circ} \mathrm{W}\right)$, in degrees $\mathrm{C}$.

839

840 FIGURE 9. Hourly (a) precipitable water and (b.) liquid water path from SHEBA microwave

841 radiometer and corresponding MERRA values, in $\mathrm{mm}$. 
843 FigURE 10. Average annual time series for near surface station temperature and corresponding

844 MERRA values for (a) Amundsen-Scott $\left(90^{\circ} S\right)$, and (b.) Scott Base $\left(78^{\circ} S, 167^{\circ} E\right)$, in degrees C.

845 Bars indicate the standard deviation of monthly val ues over the period 1979-2005.

846

847 FIGURE 11. Time series of daily downwelling longwave flux and the net downward flux from

848 Dutton et al . (1989) and corresponding values from MERRA for $90^{\circ} \mathrm{S}$, in $\mathrm{W} \mathrm{m}^{-2}$.

849 
TABLE 1. Components of the MERRA atmospheric energy budget for regions defined in Fig. 1, in $\mathrm{W} \mathrm{m}^{-2}$. The surface flux $F_{s f c}$ discounts latent heating from solid precipitation. The standard deviation over the 1979-2005 time period is indicated in parentheses.

\begin{tabular}{llrrrrr}
\hline & & $\square[\square \square$ & $-\nabla \cdot F_{A}$ & \multicolumn{1}{c}{$R_{\text {top }}$} & \multicolumn{1}{c}{$F_{s f c}$} & $A N A_{(E)} i Q_{N U M}$ \\
\hline $70^{\circ} \mathrm{N}-90^{\circ} \mathrm{N}$ & January & $-1(11)$ & $110(16)$ & $-173(4)$ & $63(5)$ & $-5(9)$ \\
& July & $2(6)$ & $81(8)$ & $2(3)$ & $-68(4)$ & $-13(5)$ \\
& Mean & $0(2)$ & $99(4)$ & $-110(1)$ & $19(1)$ & $-11(5)$ \\
Arctic Ocean & January & $-3(13)$ & $106(19)$ & $-176(4)$ & $70(5)$ & $-5(14)$ \\
& July & $3(9)$ & $96(10)$ & $-7(4)$ & $-75(6)$ & $-9(6)$ \\
& Mean & $0(2)$ & $99(6)$ & $-114(1)$ & $23(2)$ & $-9(7)$ \\
Greenland & January & $-2(19)$ & $143(26)$ & $-153(6)$ & $-1(4)$ & $4(16)$ \\
& July & $1(8)$ & $118(19)$ & $-48(1)$ & $-40(1)$ & $-32(16)$ \\
& Mean & $0(2)$ & $138(9)$ & $-112(1)$ & $-16(1)$ & $-14(9)$ \\
$70^{\circ} S-90^{\circ} S$ & January & $-1(10)$ & $78(10)$ & $-25(2)$ & $-32(2)$ & $-23(8)$ \\
& July & $-10(13)$ & $131(16)$ & $-142(3)$ & $19(2)$ & $-21(10)$ \\
& Mean & $0(1)$ & $118(6)$ & $-101(1)$ & $3(1)$ & $-22(6)$ \\
Southern & January & $2(6)$ & $97(17)$ & $58(10)$ & $-114(9)$ & $-40(17)$ \\
Ocean & July & $-7(8)$ & $91(15)$ & $-174(1)$ & $82(3)$ & $-11(13)$ \\
& Mean & $0(1)$ & $89(5)$ & $-83(2)$ & $12(2)$ & $-23(5)$ \\
Antarctica & January & $-2(10)$ & $80(11)$ & $-41(1)$ & $-21(1)$ & $-21(8)$ \\
& July & $-9(12)$ & $135(18)$ & $-134(3)$ & $7(2)$ & $-20(10)$ \\
& Mean & $0(1)$ & $124(5)$ & $-101(1)$ & $-3(1)$ & $-23(5)$ \\
\hline
\end{tabular}


TABLE 2. MERRA, CFSR, and ERA-I 1989-2005 average TOA and surface energy flux val ues for regions defined in Fig. 1 , in $\mathrm{W} \mathrm{m}^{-2}$. The standard deviation over the time period is indicated in parentheses.

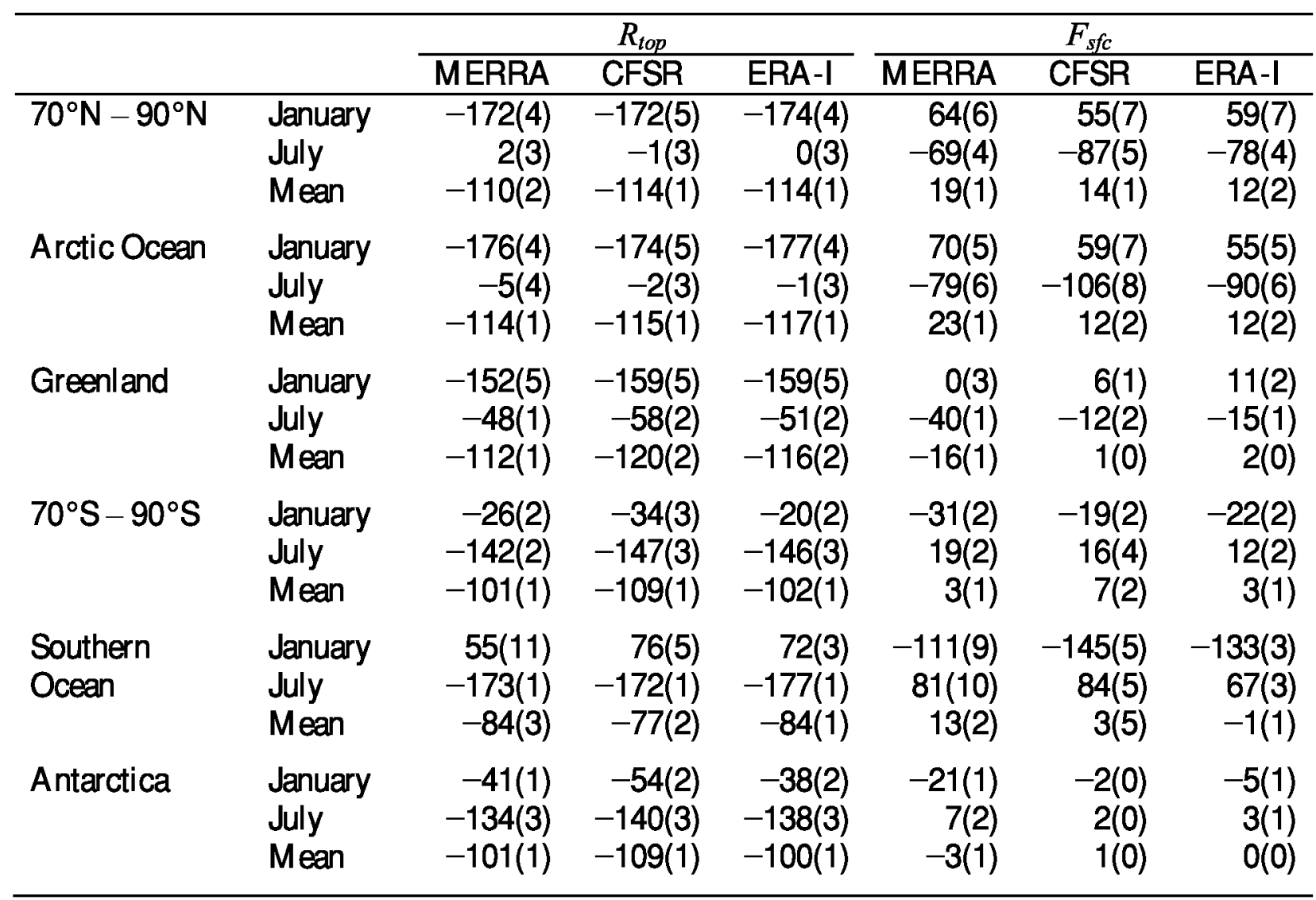




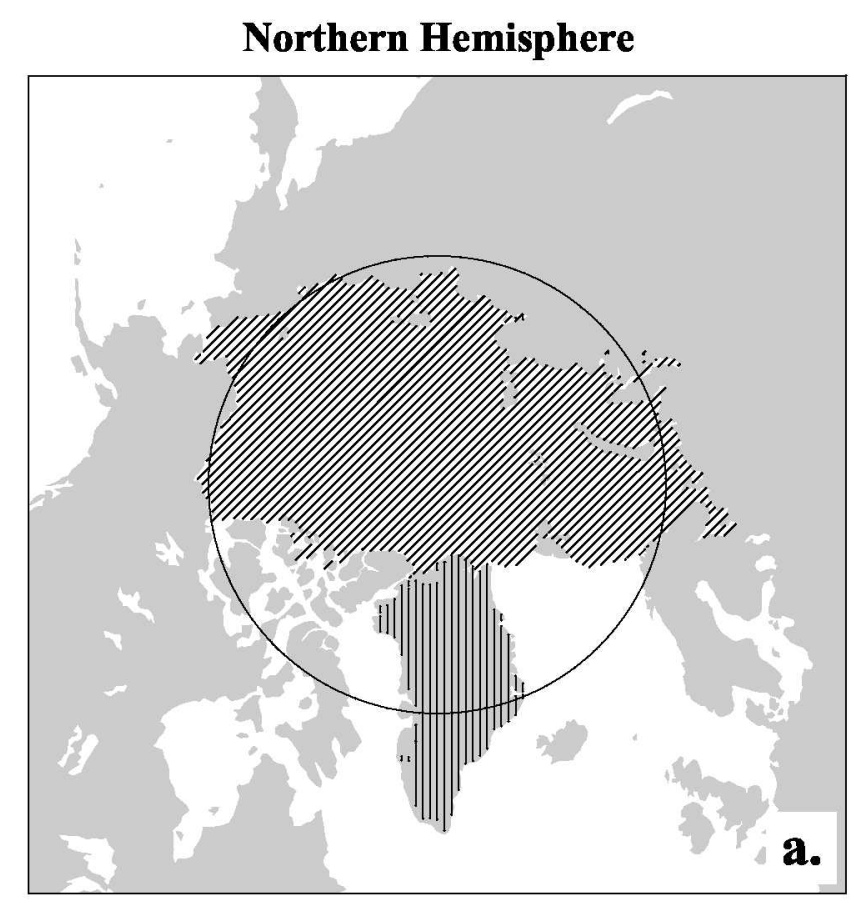

\section{Southern Hemisphere}

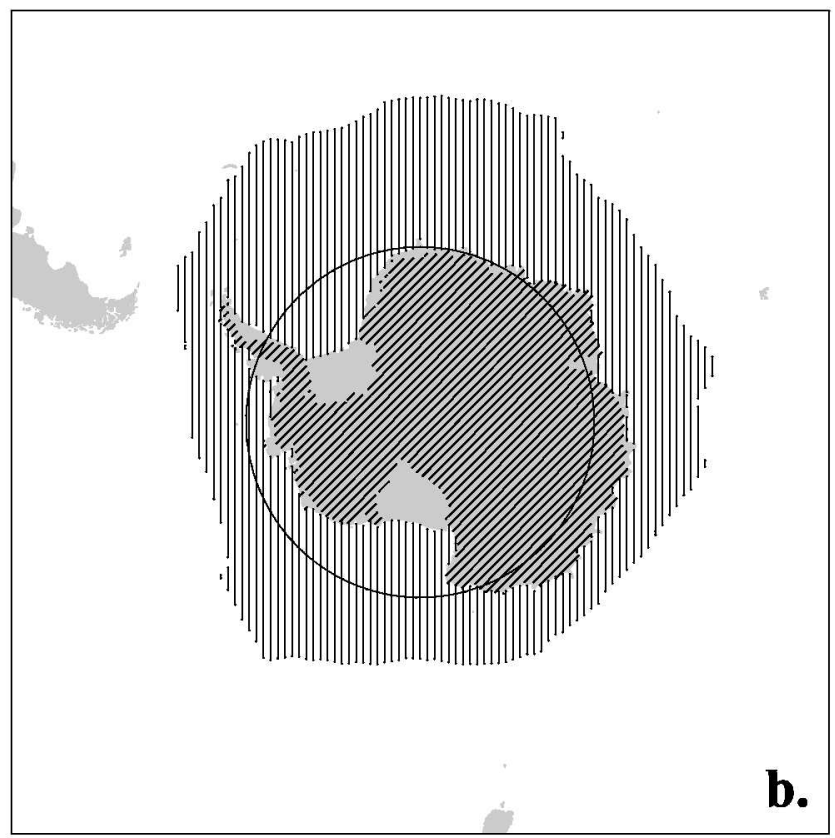

FigurE 1. Regions of study for (a) the Northern Hemisphere and (b.) the Southern Hemisphere. Bold line indicates the $70^{\circ}$ parallel. Continental areas are shaded gray. 

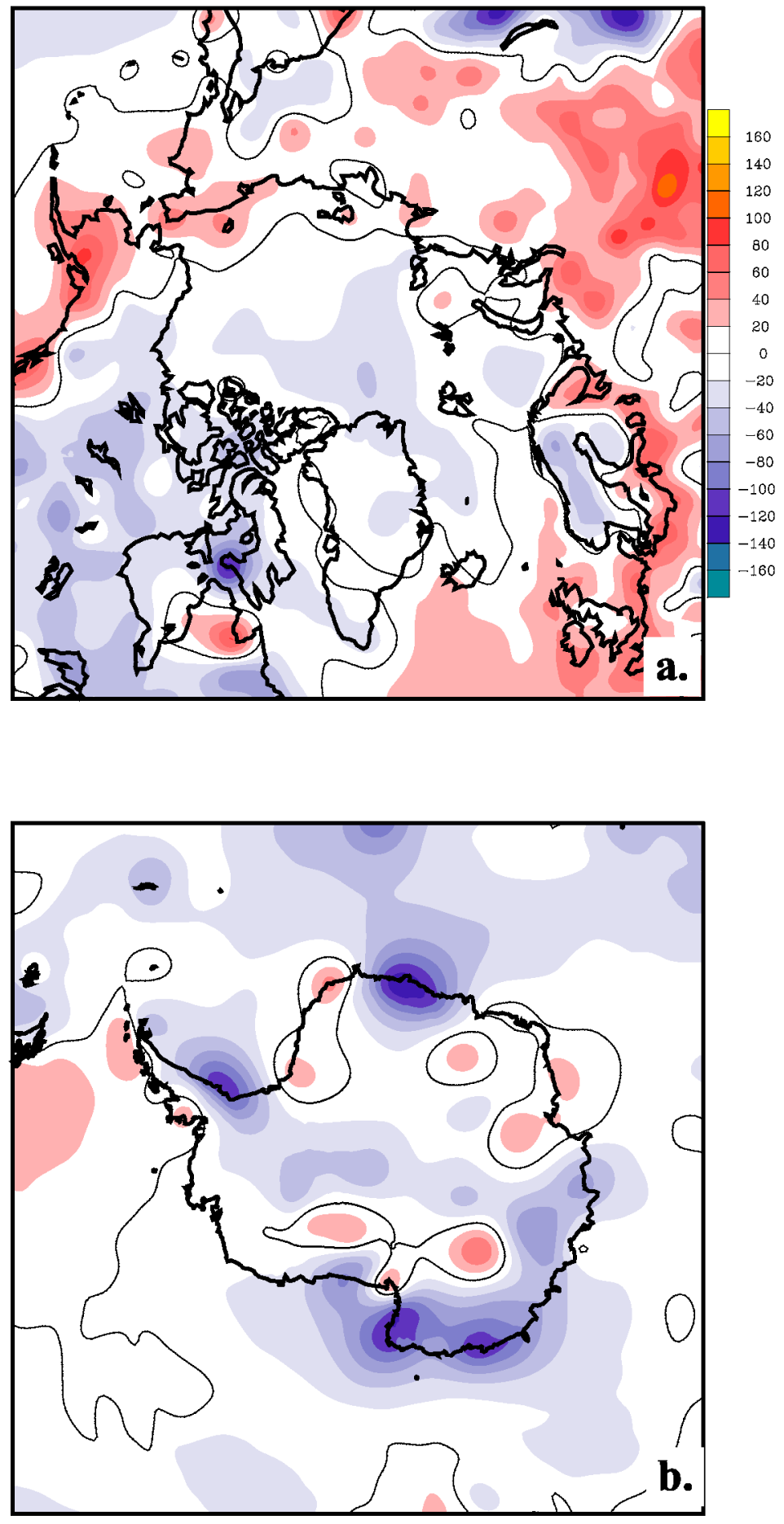

FIGURE 2. Average MERRA analysis increments field for the atmospheric energy budget (variable $A N A_{(E)}$ ) for (a) the Northern Hemisphere and (b.) the Southern Hemisphere. The contour interval is $20 \mathrm{~W} \mathrm{~m}^{-2}$. The zero contour is indicated with a solid black line. 

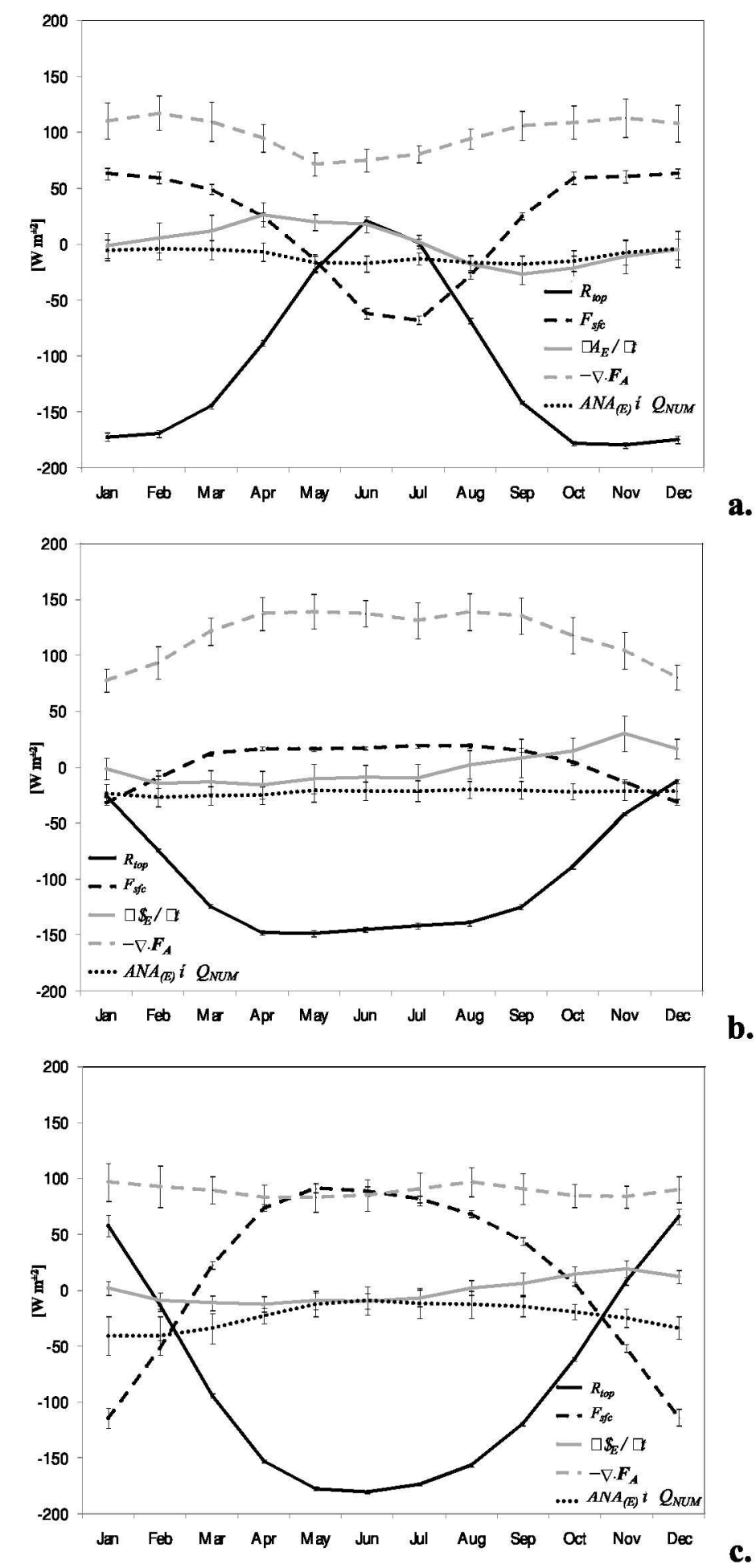

b.

FiguRE 3. Annual cycle of atmospheric energy budget components in MERRA for (a) north polar cap, (b.) south polar cap, and (c.) the Southern Ocean domain, in $\mathrm{W} \mathrm{m}^{-2}$. Bars indicate plus and minus the standard deviation for the period 1979-2005. 


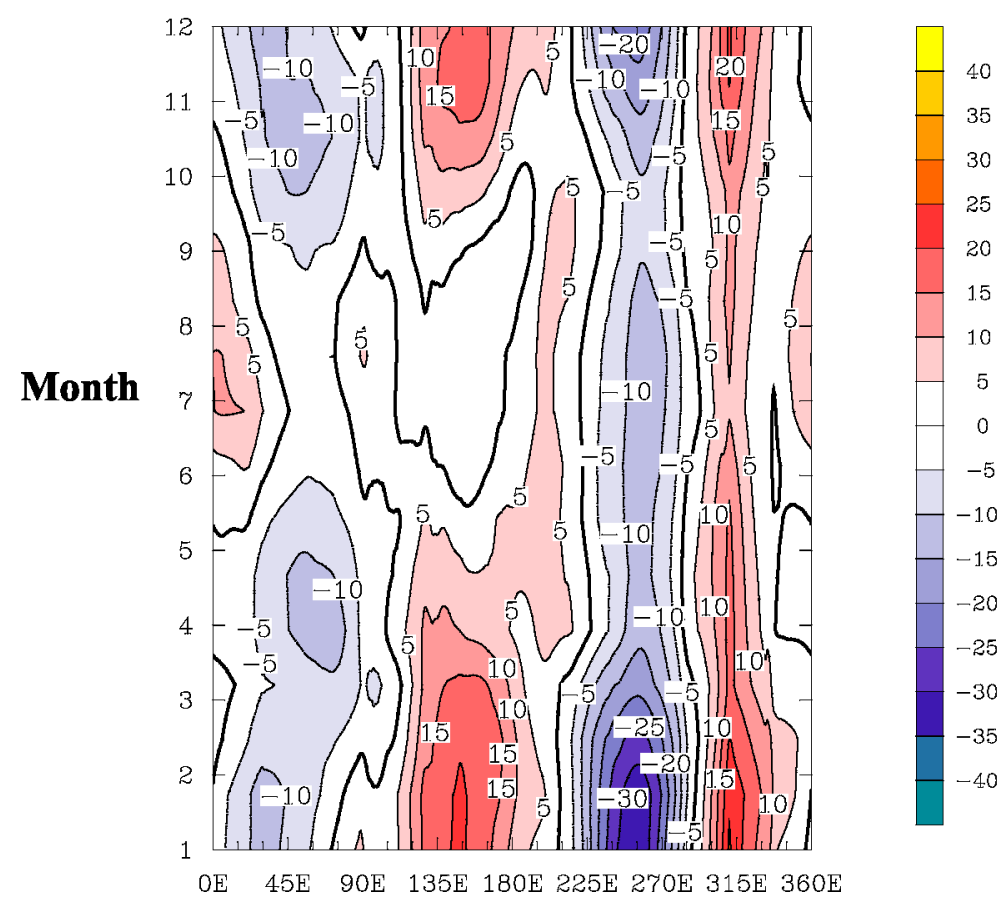

$7^{\circ} \mathrm{N} \quad$ (a.)

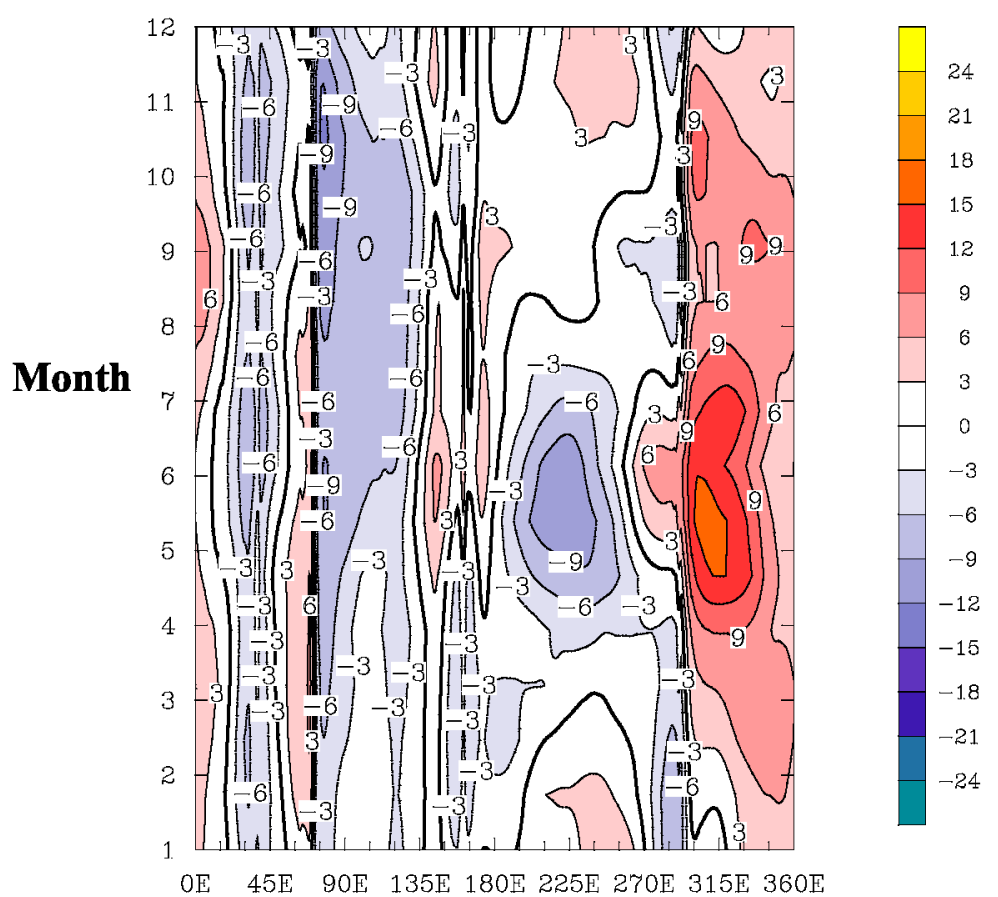

$70^{\circ} \mathrm{S} \quad$ (b.)

FIGURE 4. Average monthly meridional energy transport from MERRA (a) across $70^{\circ} \mathrm{N}$, contoured every $5 \cdot 10^{9} \mathrm{~W} \mathrm{~m}^{-1}$, and (b.) $70^{\circ} \mathrm{S}$, contoured every $3 \cdot 10^{9} \mathrm{~W} \mathrm{~m}^{-1}$. Positive values indicate northward transport. 

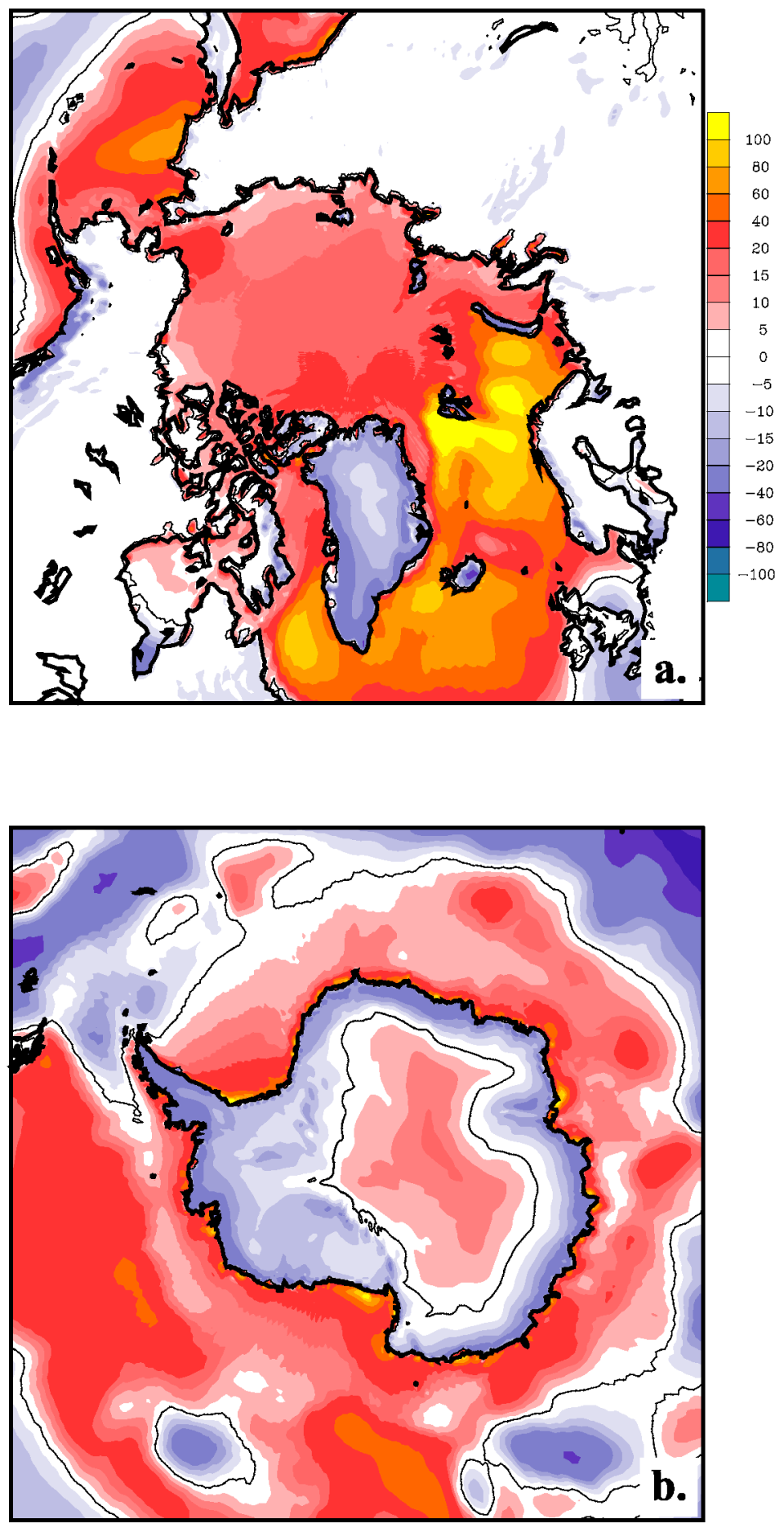

FiguRE 5. Annual average net surface heat flux from MERRA (positive upwards). Contours are plotted with an interval of $20 \mathrm{~W} \mathrm{~m}^{-2}$ and for the levels $-10,-5,0,5$, and $10 \mathrm{~W} \mathrm{~m}^{-2}$. The zero contour is indicated with a solid black line. 


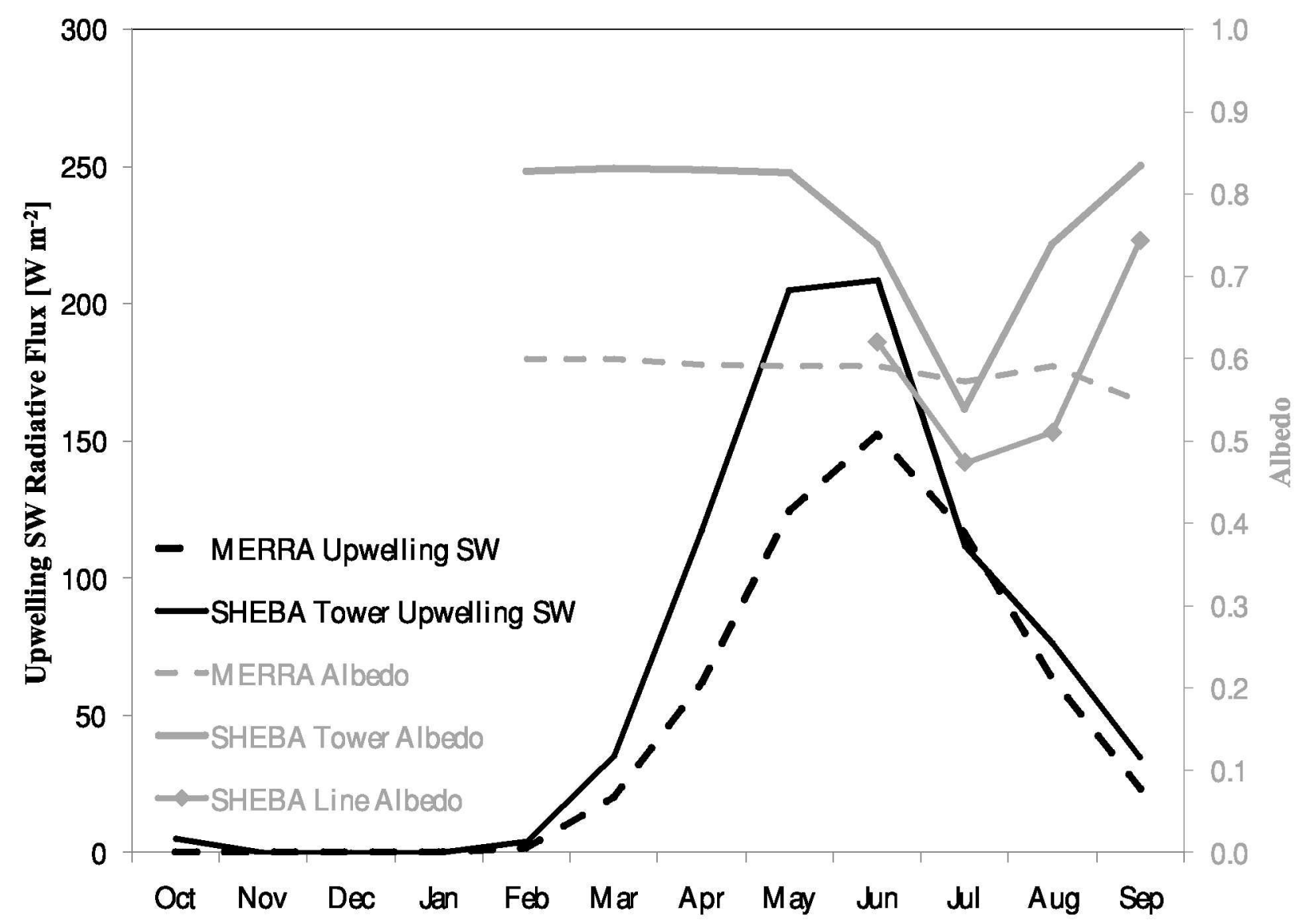

FIGURE 6. Monthly averaged surface albedo (gray) and upwelling shortwave radiative flux (dark) for SHEBA observed (solid) and corresponding MERRA values (dashed) for October 1997 to September 1998, in $\mathrm{W} \mathrm{m}^{-2}$. "Tower" values are from downward-pointing pyranometer measurements, while "line albedo" values are from surface measurements al ong a $300 \mathrm{~m}$ line. 


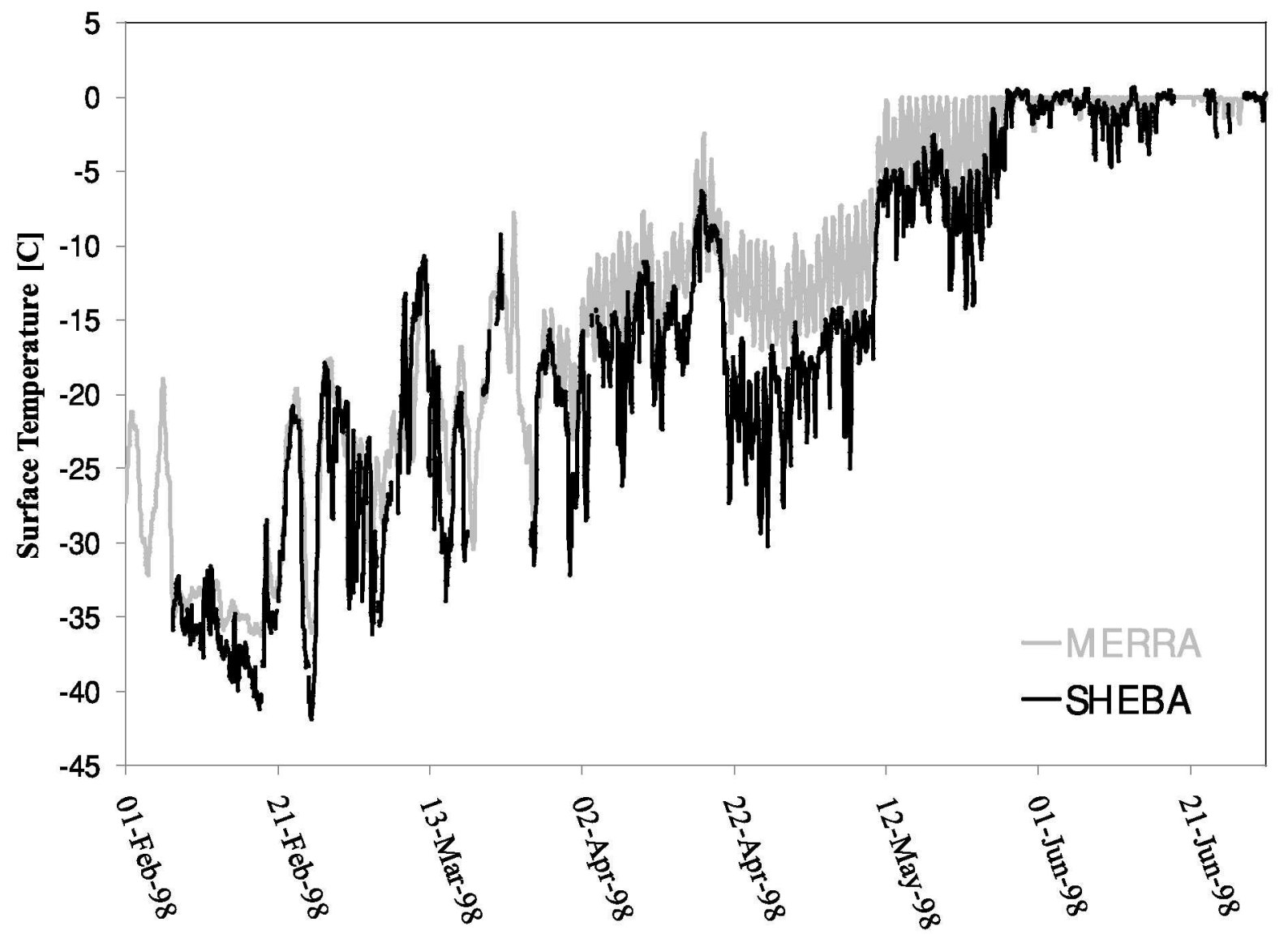

FIGURE 7. Near-surface hourly air temperature from SHEBA and corresponding values from MERRA for the period 1 February 1998 to 30 June 1998, in degrees C. 

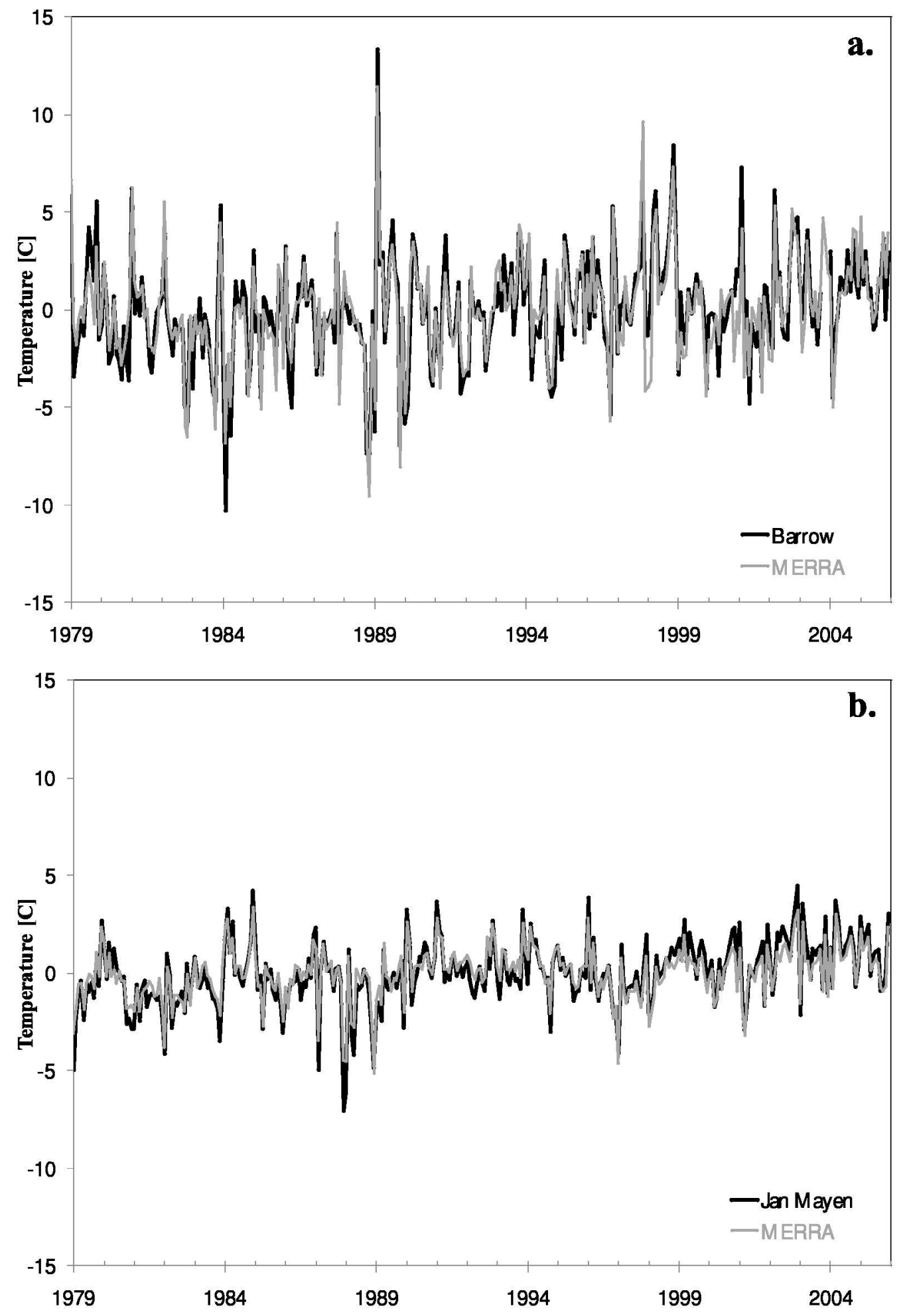

FIGURE 8. Time series of monthly averaged near-surface station air temperature anomaly and corresponding MERRA values for Barrow (left, $71^{\circ} \mathrm{N}, 157^{\circ} \mathrm{W}$ ) and Jan Mayen (right, $71^{\circ} \mathrm{N}$, $9^{\circ} \mathrm{W}$ ), in degrees $\mathrm{C}$. 

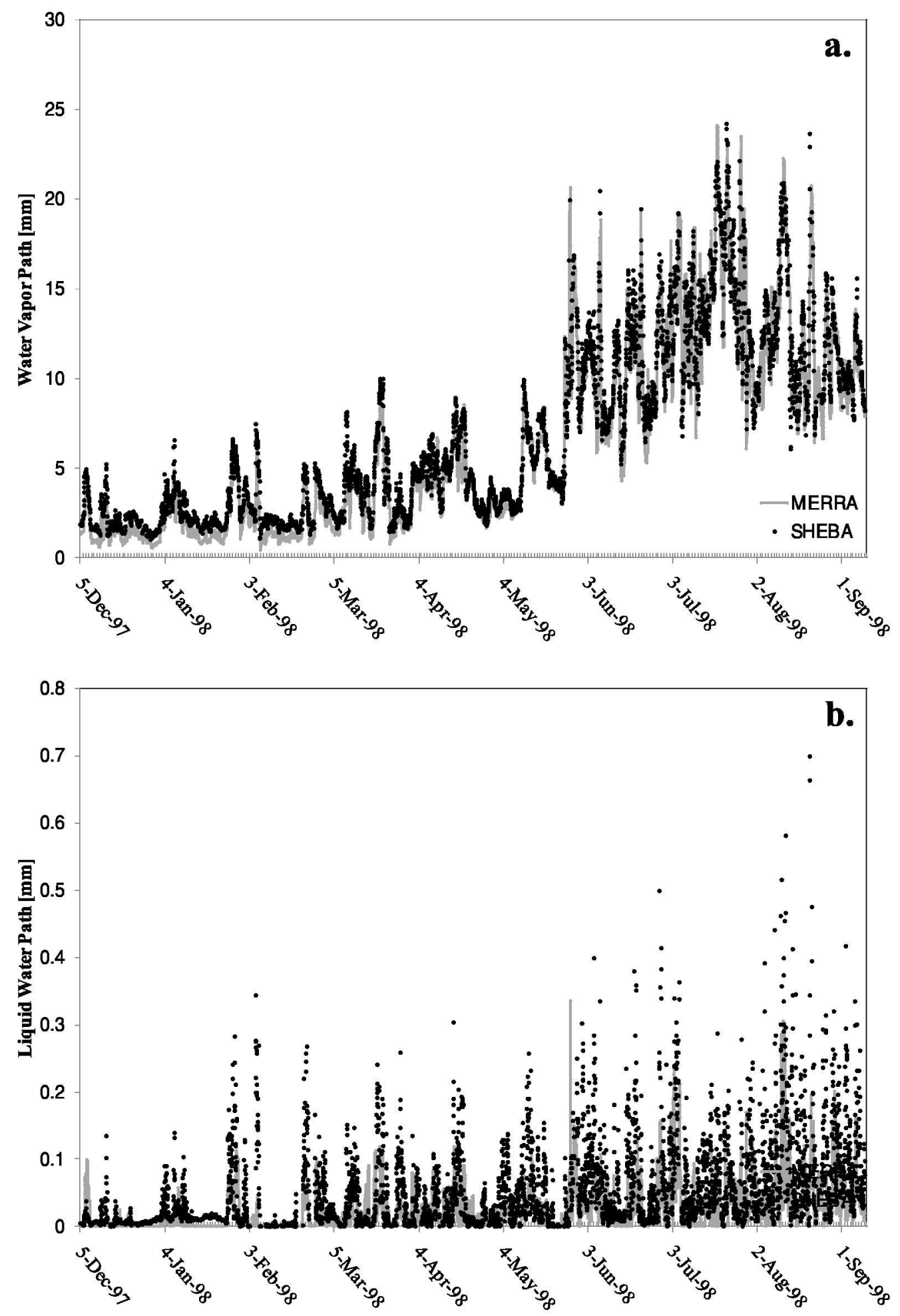

FIGURE 9. Hourly (a) precipitable water and (b.) liquid water path from SHEBA microwave radiometer and corresponding MERRA values, in $\mathrm{mm}$. 

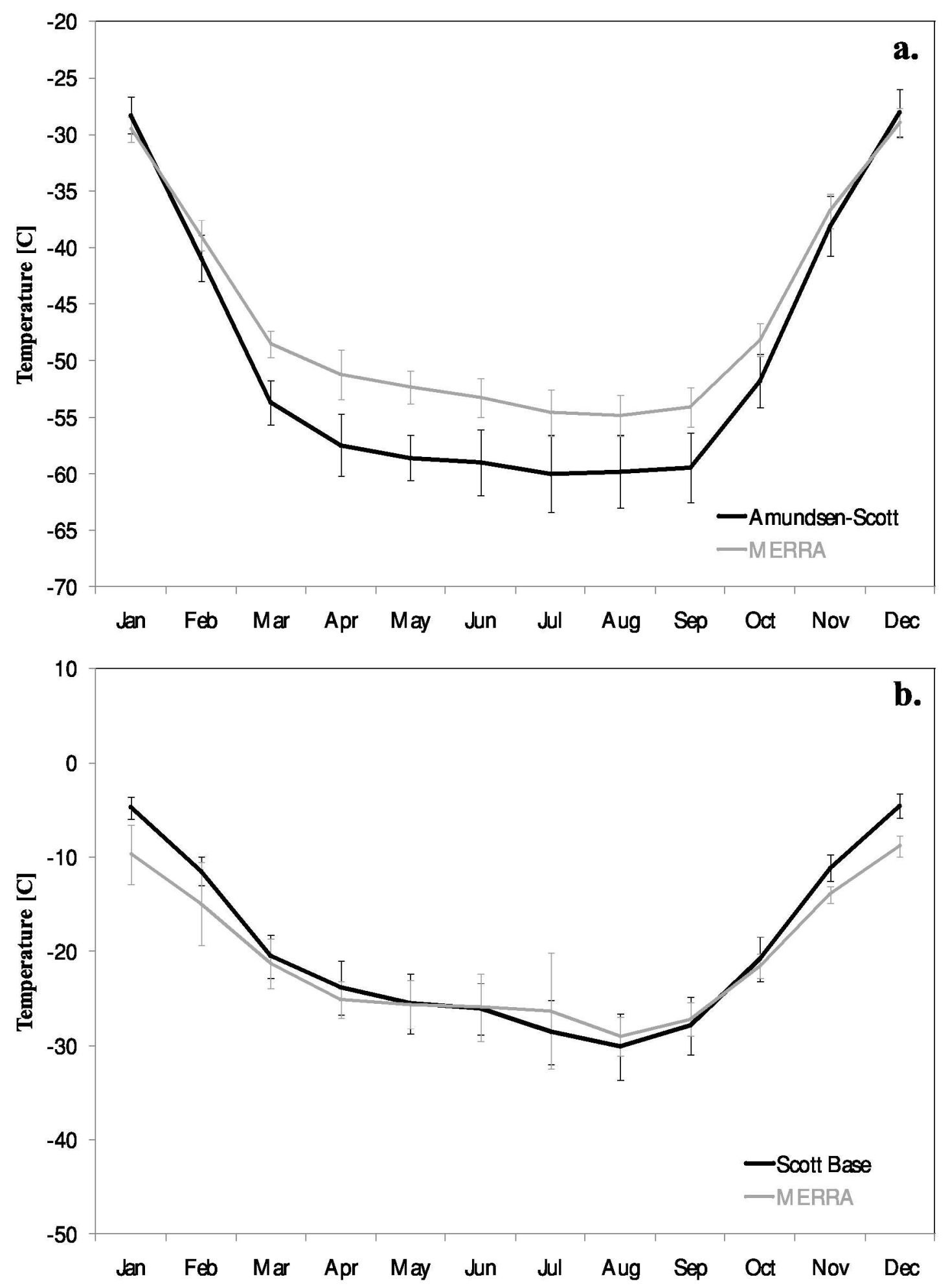

FIGURE 10. Average annual time series for near surface station temperature and corresponding MERRA values for (a.) Amundsen-Scott $\left(90^{\circ} \mathrm{S}\right)$, and (b.) Scott Base $\left(78^{\circ} \mathrm{S}, 167^{\circ} \mathrm{E}\right)$, in degrees C. Bars indicate the standard deviation of monthly values over the period 1979-2005. 


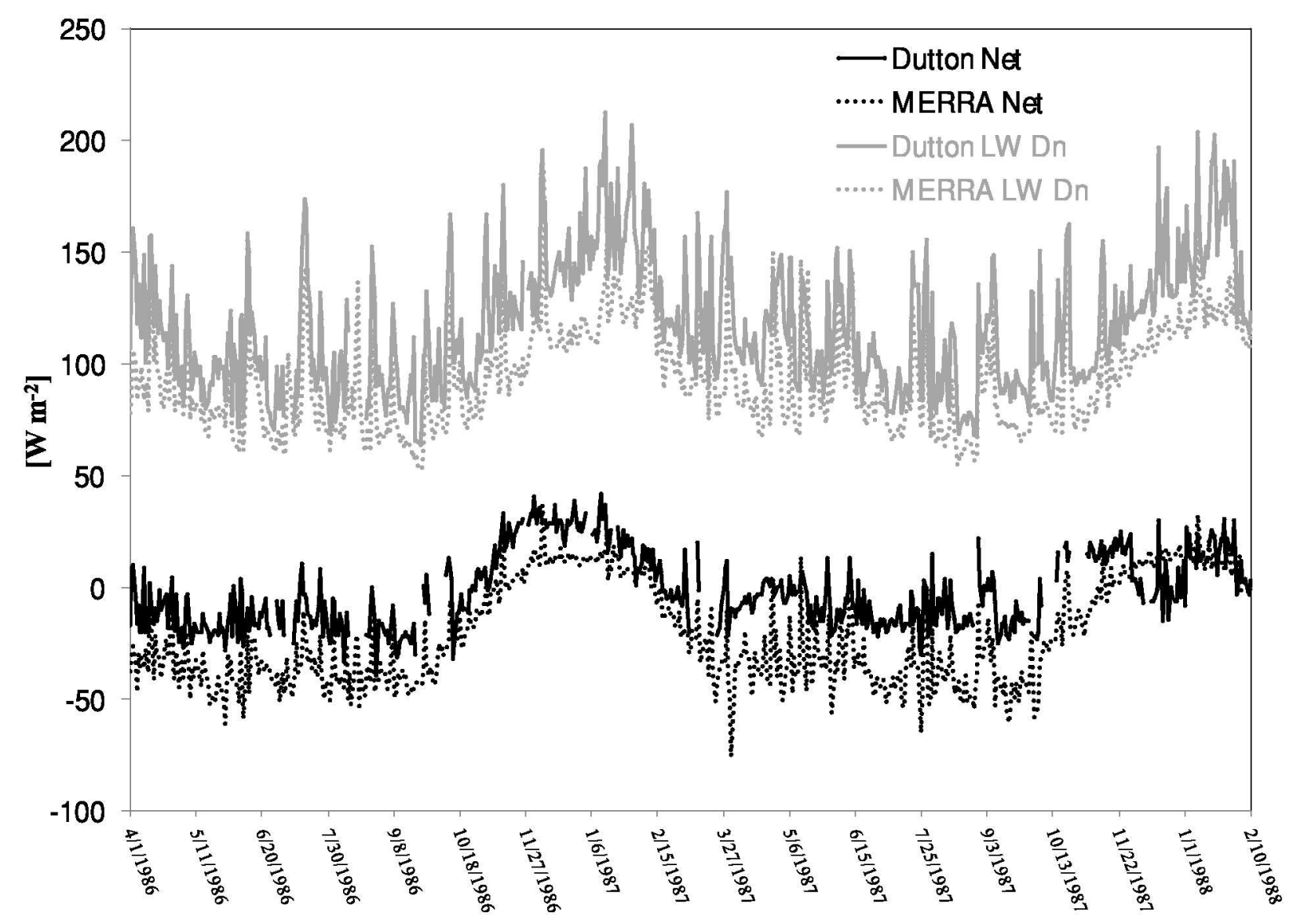

FIGURE 11. Time series of daily downwelling longwave flux and the net downward flux from Dutton et al . (1989) and corresponding values from MERRA for $90^{\circ} \mathrm{S}$, in $\mathrm{W} \mathrm{m}^{-2}$. 